\title{
Article
}

\section{The Spectatorship of Portraits by Naïve Beholders}

Trawinski, Tobiasz, Mestry, Natalie, Harland, Beth, Liversedge, Simon Paul, Godwin, Hayward J. and Donnelly, Nick

Available at https://clok.uclan.ac.uk/26213/

Trawinski, Tobiasz, Mestry, Natalie, Harland, Beth, Liversedge, Simon Paul orcid iconORCID: 0000-0002-8579-8546, Godwin, Hayward J. and Donnelly, Nick (2019) The Spectatorship of Portraits by Naïve Beholders. Psychology of Aesthetics, Creativity, and the Arts . ISSN 1931-3896

It is advisable to refer to the publisher's version if you intend to cite from the work. http://dx.doi.org/10.1037/aca0000248

For more information about UCLan's research in this area go to http://www.uclan.ac.uk/researchgroups/ and search for < name of research Group>.

For information about Research generally at UCLan please go to http://www.uclan.ac.uk/research/

All outputs in CLoK are protected by Intellectual Property Rights law, including Copyright law. Copyright, IPR and Moral Rights for the works on this site are retained by the individual authors and/or other copyright owners. Terms and conditions for use of this material are defined in the policies page.

\section{CLoK}

Central Lancashire online Knowledge www.clok.uclan.ac.uk

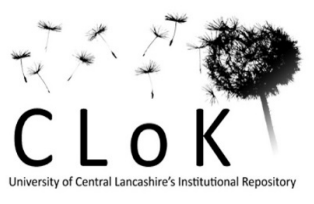


The Spectatorship of Portraits by Naïve Beholders

Tobiasz Trawinski ${ }^{1}$, Natalie Mestry ${ }^{2}$, Beth Harland ${ }^{3}$, Simon P. Liversedge ${ }^{4}$, Hayward J. Godwin ${ }^{1} \&$ Nick Donnelly ${ }^{5}$

${ }^{1}$ Department of Psychology, University of Southampton, United Kingdom

${ }^{2}$ Department of Psychology, Bournemouth University, United Kingdom ${ }^{3}$ Lancaster Institute for the Contemporary Arts, Lancaster University, United Kingdom

${ }^{4}$ School of Psychology, University of Central Lancashire, United Kingdom

${ }^{5}$ Department of Psychology, Liverpool Hope University, United Kingdom

Contact details:

Tobiasz Trawinski

School of Psychology

University of Southampton

Southampton SO17 1BJ

UK

T.Trawinski@southampton.ac.uk 


\begin{abstract}
The spectatorship of portraits by naïve viewers (beholders) was explored in a single experiment. Twenty-five participants rated their liking for 142 portraits painted by Courbet (36 paintings), Fantin-Latour (36 paintings) and Manet (70 paintings) on a 4-point Likert scale. The portraits were classified in terms of focussed versus ambiguous nature of sitter gaze and the presence of salient features in the context beyond sitters. Participants rated portraits while having their eye movements recorded. The portraits were split into regions of interest (ROIs) defined by faces, bodies and context. Participants also completed individual difference measures of attention and task focus. Results showed naïve spectatorship to be subject to attentional capture by faces. Paradoxically, the presence of salient features in the context amplified the attentional capture by faces through increasing participants liking of portraits. Attentional capture by faces was also influenced by sitter gaze and task focus. Unsurprisingly, the spectatorship of portraits by naïve beholders is dominated by faces, but the extent of this dominance is influenced by exogenous and endogenous attentional factors.
\end{abstract}

Keywords: gaze, salient features, portraiture, spectatorship of paintings 
The Spectatorship of Portraits by Naïve Beholders

Portraits are a specific type of painting motif. Critical to the portrait motif is the inclusion and central focus of an individual or group (henceforth the sitter(s)) in a painting. Previous consideration of the spectatorship of portraits has primarily considered eye position and the perception of gaze. Most notably, Tyler (1998) has shown artists frequently position an eye in portraits on a vertical axis that runs through the centre of the painting with perception of gaze influenced by sitters' head and eye position (Todorović, 2006), and that is often interpreted as fixating the spectator (Boyarskaya, Sebastian, Bauermann, Hecht, \& Tuscher, 2015). The consideration of the importance of gaze in the spectatorship of portraits should, we argue, be part of a larger endeavour to understand the spectatorship of the whole artwork that is the portrait, since portraits are not stimuli formed to deliver only gaze. The attributes of the context around sitter(s) provide information about, for example, social status and the time and place where the painting was created (see Reff, 1975; Gombrich, 1995 pp.134-148).

The present study builds on the idea that the spectatorship of paintings is spatially limited (Locher, Krupinski, Mello-Thoms, \& Nodine, 2007). Locher et al. (2007) demonstrated this in two studies where participants who were naïve to art described their holistic impression for each work. In Experiment 1 the presentation time of paintings was limited to $100 \mathrm{~ms}$ but in Experiment 2 presentation time it was unlimited. The unlimited presentation time in Experiment 2 allowed participants eye movements to be recorded as paintings were being described. Participant descriptions were coded into six independent categories of response. With respect to the present study, there were two striking results reported by Locher et al. First, the eye movement analysis showed only an average $46 \%$ of the spatial extent of paintings was inspected before participants self-terminated their spectatorship (after 32.5 seconds), and the areas that were inspected changed little from what 
had been inspected after 7 seconds. Second, the verbal descriptions offered by participants were largely limited to semantic details of objects and their arrangements, or statements about style or how much the paintings were liked. What emerges from the Locher et al. study is a view of naïve spectatorship of paintings as spatially incomplete, and driven by the semantic details of objects.

The spectatorship of portraits is dominated by the presence of faces. In fact, the presence of human faces in portraits will likely lead to the capture of attention (FletcherWatson, Findlay, Leekam, \& Benson, 2008; Langton, Law, Burton, \& Schweinberger, 2008). Faces are a special case of objects as they communicate evolutionally relevant information regarding emotion and identity. There has been much debate in the literature about whether faces are so important from a social/evolutionary perspective that they have a visuo-cognitive mechanism all to themselves, or whether face-specific processing is due to the expertise humans have developed for this class of object. There is automatic elicitation of a facespecific event related potential in response to finding faces (Bentin, Allison, Puce, Perez, \& McCarthy, 1996; Johnston, Molyneux, \& Young, 2015), and face specific activation in neural regions of the brain such as the fusiform face area in the fusiform gyrus (Haxby, Hoffman, \& Gobbini, 2000). It is clear that faces are prioritised as they are highly relevant and have specialised processing architecture. Through the activation of processes set in motion by the prioritization of faces, the faces of those painted in portraits are represented and encoded for familiarity, emotional state and gaze (Bruce \& Young, 1986; Young, 2018).

It seems almost a 'straw man' hypothesis to explore the extent to which faces are prioritised in the visual inspection of portraits. To do so would require measuring eye movements to portraits (Rayner, 2009). In particular, measuring the likelihood of early fixations being made to faces, the extent to which fixations are allocated to faces preferentially over other areas of the portrait, and the extent to which faces 'hold' gaze. In 
fact, such data can be found in studies of eye movements to a broad class of representational paintings. For example, first, Savazzi et al. (2014) measured eye movements while adolescents rated their liking of figurative paintings. Eye movements made to faces correlated positively with their liking. Second, Villani et al. (2015) measured eye movements to paintings of individuals and pairs engaged in some action. At least for paintings of individuals, there was a preference to looking at faces, especially for those who measured high in empathy. Third, Massaro et al. (2012) reported on the difference in eye movements to paintings classified as images of nature or humans, dynamic or static, color or monochrome. The importance of faces to gaze behaviour was revealed in two effects. First, gaze behaviour to paintings of nature was influenced by color and dynamism but visual inspection of painting showing human faces was not. From these studies we conclude that there is evidence that faces in portraits are prioritised for visual inspection ${ }^{1}$. Following on from these studies the first question we explore in the present study is if the prioritisation of faces is also found in the spectatorship of portraits specifically. We have little doubt that this will be so and that fixations will be prioritised to faces.

The exploration of the prioritisation of faces in portraiture logically precedes consideration of how sitter gaze might influence spectatorship. Gaze is important for humans and it is important from birth (Batki, Baron-Cohen, Wheelwright, Connellan, \& Ahluwalia, 2000; Valenza, Simion, Cassia, \& Umiltà, 1996). What starts as a bias to looking at eyes in general develops over the first three months of life into one for human eyes specifically (as opposed to, for example, the eyes of monkeys; Dupierrix et al., 2014). The importance of attending to eyes leads to gaze following at around nine months of age (Senju, Csibra \& Johnson, 2008).

Attending to gaze is important for social cognition (Birmingham, Biscof, \& Kingstone, 2009; Frischen, Bayliss, \& Tipper, 2007). In particular, it is important to the 
development of theory of mind, an important social function to understand the feelings and intentions of others (Baron-Cohen, Jolliffe, Mortimore, \& Robertson, 1997; Charman et al., 2000; Kampis, Fogd, \& Kovács, 2017). With respect to faces, the neural mechanisms dedicated to determining gaze (e.g., Carlin \& Calder, 2013) might provide spectators with a cue to what else should be attended beyond the face.

The influence of gaze on spectatorship is complex (Boyarskaya et al., 2015). Working within the tradition of art theory, Fried (1980) has suggested that portraits can be thought of as addressing spectators in an absorptive, theatrical manner, or in some cases as showing aspects of address that are both absorptive and theatrical (what Fried refers to as showing a 'double relation' of sitter to spectator). While there may be many influences on absorption and theatricality, it is evident that gaze is a major determinant of it (Donnelly et al., 2017). Gaze communicating theatricality occurs when it is directed out from the painting and towards spectators. These are the conditions that occur in portraits showing the Mona Lisa effect (Todorović, 2009). Gaze communicating absorption occurs when the sitter focuses attention on some action, object or person represented within the painting itself (Harland et al., 2014). In both cases, theatrical and absorptive gaze provide a reliable cue for spectatorship process.

A focal point for gaze in portraits can sometimes be hard to determine. When the focal point of gaze is ambiguous it is hard to classify sitter gaze as absorptive or theatrical and some artists have exploited this to create a specific effect. The portraiture of Edouard Manet is striking with respect to the frequency with which he represented gaze in an ambiguous manner by painting misaligned pupils (Donnelly et al., 2017). The effect of ambiguous gaze is to create the double-relation between spectators and sitters creating sitters that address spectators but are disengaged from them (Fried, 1980).

Although there are instances of artists producing portraits with marked gaze 
ambiguity prior to the $19^{\text {th }}$ century, at this point a range of social and technological factors (Crary, 1992, pp. 6 -14) led to portraits needing to be more than illustrations of people and their social status. For example, Manet's portraiture is often considered as showing figures, who are turned in upon themselves, temporarily preoccupied, "they are absent from the world" (Wollheim quoted in Fried, 1996, p. 344). The effect of Manet's mode of address has been described as "something like cognitive or musical dissonance," intended as a challenge, turned "towards the beholder with a strange, flamboyant indifference to that beholder" (Pippin, 2014, p. 48).

If we consider portraits from this period as a type of picture that communicates sociocognitive information, we can think of absorptive and theatrical portraits as using gaze as a cue for spectator attention. Here we classify absorptive and theatrical portraits as providing a reliable cue for attention (i.e., it is either focussed on the spectator or on some other location within or outside the space of the painting). In contrast, portraits where the gaze is ambiguous provide an unreliable cue to gaze location but a reliable cue to disengagement from the sitter's face.

The second question we address in the present study is how sitter gaze influences the spectatorship of portraits. The focal point of attention inferred from sitter gaze might be the spectator themselves, as in the case of theatrical portraits, or some other person or object within the painting, as in the case of absorptive paintings. In the case of ambiguous gaze, where is difficult to determine the focal point of attention, sitter gaze may be a poor cue for informing inspection of the painting beyond the sitter. Here we test whether gaze that unambiguously cues attention (i.e., is focussed) to a location limits the inspection of the context of portraits relative to when gaze is a poor cue for attention (i.e., is ambiguous; Donnelly et al., 2017). 
In terms of contextual information we can consider two types of portraits. The first type of context shows artefacts and an identifiable environment, which provides information about, for example, a sitter's social status or role (e.g., Zacharie Astruc painted by Manet in 1866 shows man in the chair next to books on the table bust, and domestic scene in the background; Figure 1). The second type of context shows sitters on a colored background (e.g., Henri Rochefort by Manet painted in 1881, shows a man in black jacket painted on a dark background with a light yellow reflection). The inclusion of people, artefacts and identifiable environmental objects in the context provide potential foci for spectatorship beyond the sitter. Artefacts and identifiable environmental objects in the context are likely to be salient visual features. Consideration of artefacts and identifiable environmental objects as salient visual features provides a helpful heuristic (Tatler, Brockmole, \& Carpenter, 2017). It enables us to use a saliency algorithm to give an unbiased measure of the extent to which those artefacts and identifiable objects are visually salient within the context. In this study, therefore, we measured the presence of salient features by passing portraits through an image-processing algorithm designed to detect significant change in the presence of feature hue, luminance and orientation (Itti \& Koch, 2001; Figure 1). In a third question we ask how the presence of salient features in the context of portraits influences the spectatorship of portraits showing sitters with focussed or ambiguous gaze (see also Graham \& Redies, 2010).

\section{INSERT FIGURE 1 HERE}

The question of the relative importance of the presence of faces and salient features in the context for spectatorship has been considered with respect to photographs. When measuring eye movements to photographs of natural scenes containing people, Cerf, Frady and Koch (2009; see also Zhao \& Koch, 2011) found the presence of faces to be prioritised 
relative to non-face locations with salient features, thereby demonstrating the attentional capture by faces. More importantly, Cerf et al. (2009) have shown that for locations containing salient non-face features to attract attention when those locations compete with faces at other locations, then it is necessary that their salience to be very high.

The spectatorship of paintings may be different to that of photographs so it would be wrong to immediately generalise from the Cerf et al. (2009) findings. Painted portraits are the product of artistic skills, style and paint materials and cannot be considered as literal representations of reality. As such the manner of spectatorship may be governed by different principles to those of photographs. To the best of our knowledge we do not know any study that has explored the influence of the presence of salient regions in the context of portraits on their spectatorship. It is for this reason that here we carry out such an investigation to assess the influence salient regions in the context of portraits on spectatorship.

It is possible that both sitter gaze and salience might influence a spectator's gaze behaviour by acting as exogenous or endogenous cues to attention. It is known that there is a tight relationship between gaze behaviour, attention and working memory (Godijn \& Theeuwes, 2004; Schimidt, Vogel, Woodman, \& Luck, 2002; Theeuwes, Belopoksy, \& Olivers, 2009). While the specific details of this relationship are beyond the current study, there may be some relationship between gaze behaviour, attention and working memory in spectatorship. We examine this in the present study by exploring whether individual differences in gaze behaviour are associated with those in attention and working memory. To do so, we measure performance on the Attention Network Task (ANT: Fan, McCandliss, Sommer, Raz, \& Posner, 2002) and 3-back working memory capacity test (Shackman et al., 2006). The ANT provides a measure of executive, orienting and alerting attention networks. Working memory capacity tests also provide a measure of executive attention and task focus. The goal in taking these individual difference measures was to explore whether the gaze 
behaviour made during spectatorship of portraits is subject to influence from individual differences in the tendency to orient attention or maintain task focus. The hypotheses being that an increased tendency to orient attention may lead to increased fixations to the context, whereas an increased task focus may lead to increased fixations to the face.

In summary, the present study explores how stimulus factors (gaze and salience) and cognitive factors (individual differences in orienting and task focus) influence the spectatorship of portraits. We predict that the spectatorship of portraits will be characterised by prioritised attention to faces rather than to bodies or contexts. Prioritised attention to faces will be demonstrated by rapid and prolonged fixations to faces relative to other locations in portraits. In addition we test the following hypotheses: The tendency to attend to the context will be increased by the presence of salient features and ambiguous sitter gaze. In relation to measures of individual differences, we test whether the tendency to attend to the context will be increased with increased orienting as measured by the ANT and whether the tendency to maintain focus on faces will increase with task focus.

Finally, eye movements to visual images are known to vary with task requirements (Borji \& Itti, 2014; Fuchs, Ansorge, Redies and Leder, 2011; Henderson, Shinkareva, Wang, Luke, \& Olejarczyk, 2013; Yarbus, 1967). For this reason, it is important to note that spectatorship in the present study was measured while participants provided ratings of their liking for portraits (see also Massaro et al., 2012; Savazzi et al., 2014).

\section{Method}

\section{Participants}

Twenty-five undergraduate students ( 9 males and 16 females; $M=21.04, S D=2.92$ ) from University of Southampton participated in the study. They were recruited through a university online survey responding that they were not knowledgeable about art and had 
received no art training. They received course credits for taking part. Participants completed a test of art knowledge (Jakesch \& Leder, 2009) translated $^{2}$ to English from the original German version of the questionnaire (see Appendix 1). Participant knowledge about art tended to be low $(M=8.42$ [out of 48]; $S D=6.15 ; M d n=6.5$; range $=2$ - 27). The participants were therefore classified as naïve beholders of art.

\section{Apparatus}

Tasks were presented on a View-Sonic graphics Series G225f CRT monitor with screen size $40.60 \mathrm{~cm} \times 30.80 \mathrm{~cm}$ in a darkened room. Participants were seated at a distance of $70 \mathrm{~cm}$ giving a visual angle of $30.11^{\circ}$ by $23.75^{\circ}$ for the screen. Screen resolution was $1024 \mathrm{x}$ 768 with a refresh rate of $120 \mathrm{~Hz}$. Viewing was binocular, though only movements of the right eye were recorded using an SR Research Limited Eye-Link 1000 eye tracker operating at $1000 \mathrm{~Hz}$. Head movement was stabilized using a chin and headrest. Participants responded by pressing one of the four buttons on a button-box.

\section{Stimuli}

One hundred and forty-two portraits were used in this experiment (Table 1). The image set consisted of 70 portraits by Edouard Manet, 36 by Henri Fantin-Latour and 36 by Gustav Courbet. The portraits set represents artists form a consistent art historical context. The high-resolution reproductions of paintings were uploaded from the Google Image Search. All signatures were removed using Adobe Photoshop CS6. Ninety-four of the portraits were used in Donnelly et al. (2017) study.

In a pre-test, a different set of 16 participants ( 4 males and 12 females; $M=20.69$, $S D=2.57$ ) was presented with the 142 paintings in random order on a computer screen. They were asked to rate on a scale of 0 (no ambiguity) to 5 (ambiguous): "How ambiguous is the gaze of the primary figure in the portrait?" They received the set of standardized instructions from Donnelly et al. (2017) to outline ambiguous gaze (see Appendix 2). 
Paintings were shown one at a time so were rated separately. The set of paintings was presented in a different random order for each participant.

The mean categorisation ratings are shown in Table 1 . These values were divided into three categories regarding to level of ambiguity: focused (scores of 0 -1.66), moderately ambiguous (scores of $1.67-3.33$ ) and highly ambiguous (scores of $3.34-5$ ). As a result of rating categorization, 51 paintings were classified as focused, 87 as moderately ambiguous, and 4 as highly ambiguous. For the further analyses, the 91 moderately and highly ambiguous portraits were merged into one category (ambiguous) because of the small number of paintings in the highly ambiguous category ${ }^{3}$.

Each portrait painting was split into regions of interest (ROIs) of face ${ }^{4}$, body and context. Some paintings contained only a single instance of each ROI while others contained multiple face and body ROIs. The hypotheses laid out in the Introduction require specification of faces and contexts only. To do so leaves the body part of portraits unspecified. Rather than leaving portraits partially defined, we also specified a body ROI. We specific this ROI despite having no specific hypothesis with respect to it in order that all fixations are considered in the analyses.

The paintings were also passed through the Itti and Koch (2001) saliency toolbox using its default settings. As a result of the running of the Itti and Koch model, 41 paintings were classified as containing no salient features in the context (23 ambiguous, 18 focused) and 101 paintings with salient features in their context (68 ambiguous, 33 focused). The mean number of salient features present in the context ROI, when at least one was present, was $2.59(S D=2.46)$ and $2.33(S D=2.58)$ for paintings where the sitter had an ambiguous and focused gaze respectively. The classification of images as ambiguous or focused, the number of faces ROIs and salient regions identified in the context of each painting is reported in Table 1. Portraits were presented centrally on the screen, retaining their original ratios but 
scaled to fit a height of $24.50 \mathrm{~cm}$ on the screen and giving the visual angel of $19.85^{\circ}$. Widths varied between 17.29 and $50.38 \mathrm{~cm}$. this creased a visual angles between $14^{\circ}$ and $40.82^{\circ}$.

\section{INSERT TABLE 1 HERE}

\section{Design and Procedure}

Participants were tested on a computerised battery of tasks prior to the portrait rating study. These tests measured executive functions as working memory capacity test in two versions of the 3-back task: visuospatial and verbal (Shackman et al., 2006); and the orienting, alerting and executive components of the Attention Network Test (Fan et al., 2002). Participants then completed the rating study of the portraits while their eye movements were recorded. The rating study began with a standard nine-point calibration procedure. The eye tracker was calibrated to less than $0.5^{\circ}$ error. Trials started with a fixation point centred on the screen. Once this point was fixated, a portrait was presented and remained on the screen until a response was made. Participants were asked to judge their liking of the portraits on a four-point scale ( 1 - not pleasant at all, 4 - very pleasant). Responses were made via a four-button response box. The inter-trial interval was $500 \mathrm{~ms}$. Participants rated all portraits and the order in which the portraits were presented was randomised.

\section{Results}

The results are structured to consider (a) eye movements to face, body and context ROIs; (b) the impact of sitter gaze and salient features in the context ROI on eye movements to all ROIs, and (c) the association of attentional orienting and task focus, and liking on gaze behaviour. Analyses of eye movements were focussed on the number of fixations to ROIs and the mean fixation duration (see Rayner, 2009). 


\section{Outliers and Exclusion}

Fixations shorter than $60 \mathrm{~ms}$ or longer than $1200 \mathrm{~ms}$ were removed. Fixations that coincided with display onset or the response were also removed. This led to $3.87 \%$ of data being excluded. The final data set consisted of 59056 fixations. One participant was excluded from all analyses because of a technical failure, which had led to some eye movements not being recorded.

\section{Data Normalization}

The face, body and context ROIs areas were divided by portrait size in order to express the mean ROI area as percentage of whole paintings. To normalise the number of fixations to ROIs percentages were divided by proportions of mean fixations made to ROIs relative to the mean total number of fixations for each painting. The ratio of normalised fixations gives a score of 1 if the proportionate number of fixations matches the proportionate area of ROIs. A score exceeding 1 indicates more fixations being made to an ROI than predicted by a uniform distribution. A score below 1 indicates fewer fixations being made to an ROI than predicted by a uniform distribution.

Fixations durations were calculated as the mean fixation duration for each ROI. The descriptive eye movement statistics are presented in Figure 2.

The fact that there are different numbers of paintings within each category as well as different numbers of paintings within each category contributed by each artist is potentially problematic. To overcome potential difficulties associated with different numbers of stimuli per condition, we analysed data using Linear Mixed-effects Models (LMMs). The analyses are ordered such that questions are addressed separately. All of them were processed in R version 3.3.2 (R Core Team, 2016). Models were fitted using the lmer4-package (Bates, Mächler, Bolker, \& Walker, 2015) and MASS-package (Venables \& Ripley, 2002). The random effects were structured for items and participants including slopes for all fixed effects 
and correlation. The full random structure was trimmed down for those models that did not converge or had a correlation equal zero or one ${ }^{5}$. The $t$-values equal to 1.96 or higher were interpreted as significant because of the fact that for high degrees of freedom the $t$ statistic in LMMs approximates the $z$-statistic (Baayen, Davidson, \& Bates, 2008).

\section{INSERT FIGURE 2 HERE}

\section{Overall fixations to faces, bodies and contexts}

Participants made $78 \%$ of their first eye movement after the offset of the fixation cross to the faces, $17 \%$ bodies, and $5 \%$ contexts. We then tested whether participants made more and longer fixations to face than body and context ROIs. The fixed factor in the LMM was type of ROI (face versus body versus context) with normalised fixations made to faces as the baseline. More fixations were made to faces than to bodies or the context $(M=40.15, S D$ $=44.28$ versus $M=7.09 S D=5.34 ; M=.14, S D=.18$; respectively; see Table 2). With respect to mean fixation duration, fixations were longer to faces than to bodies or contexts $(M$ $=330.78, S D=121.85 ; M=251.60, S D=127.02 ; M=159.40, S D=156.22$; see Table 2). In sum, fixations were made extensively to faces relative to bodies or contexts and for a longer duration.

\section{INSERT TABLES 2 AND 3 ABOUT HERE}

\section{The impacts of sitter gaze and feature saliency on spectatorship}

With respect to analyses of normalised number of fixations and fixation durations, the LMM modelling was processed in two steps for both Body and Context ROIs because on some trials participants made no fixations to the Body or Context ROIs. First, the number of 
fixations was treated as a binominal variable using logistic GLMMs. Second, the LMMs were run using log-transformed normalised fixation data to increase the normality of the data distribution. Only trials where fixations were made to ROIs were included in the LMM. The means and standard deviations are reported in Table 3, results of the GLMM's are reported in Table 4, and for the LMM's in Table 5. The fixed factors in these models were type of Gaze (ambiguous versus focused) and Saliency areas in the context (salient versus non-salient).

With respect to normalised fixations made to faces, these data were processed using the log-transformed normalised data only. Because the faces were rarely skipped during looking at the portrait, we do not report the GLMM analysis of this measure. As fixations were almost always made to faces only the LMM analysis provide meaningful results.

\section{INSERT TABLES 4 AND 5 ABOUT HERE}

Number of fixations to the face. With respect to the LMM analyses, the main effect of salience was significant but the main effect of gaze and the interaction between gaze and saliency did not reach significance. Participants made more fixations to faces when salient features were present in the context than when they were absent.

Number of fixations to the body. With respect to the GLMM, neither of the main effects of gaze and saliency nor the interaction between gaze and saliency reached significance. With respect to log-transformed normalised fixations and LMM, neither the main effects of saliency and gaze nor the interaction between them reached significance.

Number of fixations to the context. With respect to GLMM, neither the main effects of gaze or salience nor their interaction approached significance. With respect to logtransformed normalised fixations, the main effect of saliency was significant but the main effect of gaze and the interaction between gaze and saliency did not reach significance. When 
fixations were made to the context, more were made when salient features were absent than present.

Mean fixation duration to the face. With respect to GLMM, neither the main effects of gaze and salience nor their interaction approached significance. With respect to logtransformed mean fixation duration, the main effect of saliency and the main effect of gaze did not reach significance but the interaction effect between gaze and saliency approached significance. There was a trend for mean fixation durations to the face were significantly longer when the context contained salient features and sitter's gaze was focused (Figure 3).

Mean fixation duration to body and context. No main effects or interactions reached significance in either GLMM or LMM analyses.

\section{INSERT FIGURE 3 HERE}

Power Analysis. Brysbaert and Stevens (2018) noted that repeated measures designs will have sufficient power to detect a typical effect size in psychology when the number of participants multiplied by the number of stimuli exceed 1600 observations per condition. In the present study the total number of observations was 3408 .

In addition, simulations were run using simR to estimate the power of the experiment to reveal significant results for eye movements made to faces (Green \& MacLeod, 2016; Green, MacLeod, \& Alday, 2016). The power was estimated on the basis of 1000 random samples. With respect to the number of fixations made to faces, the power for the saliency as a fixed factor was $98.8 \%$ for the observed effect size. With respect to the mean fixation duration to faces, the power to find the interaction between gaze and saliency fixed factors was $62 \%$ for the observed effect size. 
Finally, we note that one participant had a higher art knowledge score than the other participants (27 versus a maximum score of 20). The set of analyses were re-run excluding this participant. The significance and pattern of effects was unchanged.

Liking Judgments. The normalised mean number of fixations and fixation durations to face, body and context ROI were calculated for each portrait and correlated with mean liking judgments. This analysis explored whether there was a relationship between eye movements behaviour and liking judgments (see Table 6). Liking was positively associated with the normalised number of fixations made to face but not to the body or context ROIs.

We reported earlier that the presence of salient features in the context increased the number of fixations to face ROIs. A stepwise multiple regression was performed where mean liking was predicted by the number of salient regions in the context and normalised number of fixations to explore whether the association between liking judgements and normalised number of fixations to faces was mediated by the presence of salient features in the context. A significant regression equation was found, $F(1,140)=7.87, p<.01$. The multiple correlation coefficient was .23 , indicating approximately $5 \%$ of the variance in liking judgments was accounted for by the number of salient features in the context. Each additional salient feature in the context increased liking of paintings by .03. The normalised number of fixations was not entered into the equation at step 2 of the analysis $(t=1.71, p=.09)$. The regression model was significant and showed the number of salient features in the context to predict liking.

INSERT TABLE 6 HERE

The association of spectatorship with cognitive abilities. Performance on the ANT and the verbal and spatial 3-back tasks was correlated with participants' normalised mean 
fixations and fixation duration, averaged across all paintings (see Table 7 and 8). Two facts are worth noting. First, there is evidence that attentional orienting is positively associated with fixations to the context. Second, there is evidence that performance in the verbal and spatial 3-back task is negatively correlated to normalised mean fixations to the body but positively associated with fixations made to the face. The correlations are not corrected for multiple comparisons.

\section{INSERT TABLES 7 AND 8 HERE}

\section{Discussion}

The present study provides evidence in support of four key findings with respect to spectatorship when naïve beholders rated their liking of portraits. First, fixations to portraits are primarily made to faces rather than to bodies or the context, with these fixations being of long duration. Moreover, first fixations were typically made to the face rather to the body or context. Second, the presence of salient features in the context increased the number of fixations to faces (but not bodies) and reduced fixations to the context. Third, the sitter's gaze influenced the length of fixations to faces but only when salient features were present in the context. Fourth, better attentional orienting was associated with increased numbers of fixations to the context, and better ability to maintain task focus was associated with shifting fixations from bodies to faces. Finally, considering all portraits together, the number of salient features in the context also predicted spectators liking of portraits. We now consider what these findings mean in relation to the hypotheses laid out in the Introduction.

The spectatorship of portraits by naïve beholders is dominated by fixations to faces. In fact, dividing normalised fixations shows that fixations to faces were 286 times more likely than to the context. This difference is further magnified by the fact that fixations to 
faces had longer fixation durations than those made to either bodies or contexts. Faces are known to capture attention in visual search type experiments (see Bindemann \& Lewis, 2013) but the images of paintings used in the present study are quite different stimuli to those used in visual search studies. More broadly, the images of paintings used in the present study are very different from the photographs used in many other visuo-cognitive experiments, as pictorial artworks are not photographs or representations of moments in time in the real world. Furthermore considered in terms of the their representation of faces, faces in painted portraits tend to exhibit different properties to those shown in photographs (e.g. Graham, Pallet, Meng, \& Leder, 2014; Hayn-Leichsenring, Kloth, Schweinberger, \& Redies, 2013; Humphrey \& McManus, 1973; Costa \& Corazza, 2006; Schirillo, 2007). Despite these differences, the present study supports the findings of Massaro et al. (2012) in confirming the over-riding importance of faces when naïve spectators attend to painted portraits.

The fact that we report faces to exert such a striking influence on spectatorship of portraits must be understood in a specific context. For the most part participants in experiments rarely view images for longer than is required to achieve some functional goal (i.e., to find or recognise a face). However, paintings do not exist to achieve a simple functional goal or to be viewed in the minimum possible time. Rather they are often stylised, have aesthetic value and are intended to be the subject of prolonged visual exploration and judgement. The participants in the present study we able to explore the images for as long as they wished before rating them. The fact that faces captured attention in the present study is striking in that the act of spectatorship might be thought of as implicitly encouraging exploration beyond faces to the context.

The importance of this finding would be compromised if faces always appeared at the same position in relation to the initial fixation cross. The position of the fixation cross was centred on the screen and most likely to be within the body ROI of the paintings following its 
offset. This being the case, the position of the initial fixation cross cannot have benefitted the face over the body. The point to conclude is that the evidence of attentional capture by faces in portraits is not compromised by the position of faces relative to centred fixation cross.

In contrast to the fact that the evidence of a raised fixation rate to faces is not compromised by the position of faces in portraits, the same is not true for fixations to bodies. We had no specific predictions with respect to fixations to bodies but the data showed bodies to be fixated less than faces but more than contexts. The fact that the fixation cross tended to sit within the area of the body ROI raises the possibility that the raised fixations to bodies relative to the context is an artefact of the initial fixation post the offset of the fixation cross. The likelihood that this is the case is raised by virtue of the face that the individual difference data show task focus to be negatively associated with the number and length of fixations to bodies.

To provide some relevant data, Figure 4 plots the probability of fixating the body and face as a function of number of fixations made to the paintings. Figure 4 confirms the early capture of attention by faces. However, it does not suggest the fact that bodies are fixated immediately after stimulus onset. In fact, fixations to bodies peak around the fifth fixation. We conclude that the evidence of raised fixation probability to the bodies is not compromised by their position with respect to the fixation cross. In other words, fixations to the bodies are more likely than to the context, but not as great as to faces.

\section{INSERT FIGURE 4 HERE}

The presence of salient features in the context of portraits raised fixations to the face more than to the context itself. Salient features in the context may have attracted attention for those participants with a propensity to orient attention. It is important to remember that in this 
study we used evidence of salient features as a proxy measure for artefacts (i.e. objects, buildings etc.) but it is neutral in respect of the scene/object semantics associated with the presence of artefacts in the context. It seems likely that the coherence in the arrangement of artefacts in the context provides a gist in which to consider the sitter. Gist is typically thought of as being computed early in scene inspection from rapidly computed low spatial frequency information such that eye movements are made to informative locations within the scene (Castelhano \& Henderson, 2008; Oliva \& Torralba, 2006; Rayner, 2009). What the current study suggests is that naïve spectators of portraiture do not prioritise the inspection of contextual information but process it as a scene gist. The existence of objects and place in the gist provides an important contribution to the experience of the spectator. In fact the more salient features present in the gist the more the spectatorship is focussed on the face and liking increased. It is noteworthy that recent models of visual search that also consider issues from scene perception place selective search in a distinct processing pathway from gist processing (Wolfe, Võ, Evans, \& Greene, 2011). Relating this model to the present case of the naïve spectatorship of portraiture suggests faces are captured by attention in the selective pathway and the gist is processed in the non-selective pathway.

Sitter gaze exerted strikingly little influence on the eye movements performed to faces or contexts during spectatorship. We hypothesised that gaze ambiguity would allow increased inspection of the context, in part because of the challenge that such gaze poses for determining the sitters focal point of attention (see Donnelly et al., 2017, experiment 2). However no such effect was found. One conclusion we draw is that when determining liking the spectatorship of naïve spectators does not automatically follow gaze or seek to establish foci of attention from gaze. It is, however, important to note that the task used in the present study required only determining liking and the failure to show gaze as important does not mean that spectators are always insensitive to gaze. Previously we have reported gaze 
ambiguity to increase fixations to the eye region relative to those not displaying ambiguity (Donnelly et al., 2017) when asked to consider how sitters 'address' spectators.

What emerges from this study is an account of the spectatorship of portraits by naïve beholders that is subject to the influence of attentional capture by faces, but also by the processing of scene gist. We make one further point in relation to this conclusion. It might have been that faces were prioritised by spectators but that, given time, they would also attend more to the context. If this was the case, and participants felt rushed to make their liking judgements, then it would change our conclusion from one of overall strategy to one of time-course. With respect to this point we refer back to the study of Locher et al. (2007) and the fact that the mean time to make a decision in this study was $4673 \mathrm{msec}$. While enforcing a longer viewing time might have increased fixations to the context, we suspect that this would probably not happen. Enforcing prolonged viewing would probably not change the overall pattern of spectatorship (see Locher at al., 2007; for a related finding in relation to searching for improvised explosive devices in the real world scenes Godwin et al. 2015).

We do not know if the present results would generalise to the presentation of real portraits in actual galleries as opposed to digital reproductions on a monitor. Many factors are different across these two modes of presentation (i.e. visual angle, stimulus size, texture, body and head movements, initial point of fixation, material presence, atmosphere etc.). These are general concerns that might be raised of any study showing paintings to participants via a computer screen. What we can say is that it is for future studies to explore whether these factors transform naïve spectatorship such that its strategy is qualitatively different from that described in this study. Our intuition is that viewing portraits in a gallery may not lead to data much different from those generated in the present study.

There is one piece of evidence that is pertinent to the issue of the inspection of faces in the context of a painting viewed in a gallery setting is from Harland et al. (2014) study of 
inspection of the Bar at the Folies Bergère. In that study, participants were asked to describe the painting as their eye movements were measured. The task implicitly opened up the issue of the inspection of the whole painting. The data showed that, for naïve spectators, the face of the woman who is the focus of the painting dominated viewing (see Figure 3A in Harland et al., 2014), with patterns of inspection often moving between the triad of the woman, her reflection and that of a man set to the right of the painting. Despite changes in task and context of the display of the image between that study and the present one, the fundamental importance of the face to rating liking and evaluating the paintings remained similar.

Some may consider that the results presented here represent findings that relate only to the portraits used here, or more precisely, are affected by the selection of paintings by three artists that formed the stimulus set. The works were chosen from artists where, together, the set of images would form works from roughly the same period, working within the same style (Fried, 1996, pp. 407 - 412), have a range of types of contexts from busy to sparse, and where gaze would vary from ambiguous to focussed. Any systematic variation across artists was controlled statistically rather than through the partial selection of images. Moreover, our participants were naïve to pictorial artworks and ill-informed as to specific artists and their works, status, place in art history etc. We found no evidence to suggest that specific items drove the effects reported in our analyses despite works from each artist sitting within each of the four categories formed from the presence or absence of salient features in the context and focussed or ambiguous gaze.

It is right, however, to be cautious in drawing conclusions. Three issues might limit the generality of the findings. First, it might be that the dominance of faces and the effect of salience on inspection of faces on spectatorship would be different in more abstract paintings. In particular, atypical face shape (e.g. Modigliani, Madame Zborowska, 1918), organisation (e.g. Picasso, Portrait of Ambroise Vollard, 1910) and threatening facial expressions (e.g. 
Bacon, Study after Velazquez Portrait of Pope Innocent X, 1953) may reduce attentional capture. Likewise, gist processing may be impeded by abstract representations of scene structure (e.g. Chagall, The Blue Circus, 1950), colouring (e.g. Matisse, Harmony in Red, 1926-27) and depth (e.g. Picasso, Jacqueline in Turkish Costume, 1955). It is for further studies to determine if the findings we report in the present study generalise to these types of portraits.

The second reason to be cautious about the findings is that the present data reveal the viewing strategy used by naïve beholders when rating their liking of portraits. The ratings taken in the present study were judgements of whole paintings. Schulz and HaynLeichsenring (2017) suggest that the physical beauty of a sitter's faces, as distinct from the rest of the painting, is also important in determining liking. If participants had interpreted our instructions as one of determining facial beauty alone then it is likely that the importance of salient features in the context would, we suggest, have been minimal as a result of enhanced selective attention to faces.

The third reason to be cautious about the findings relates to the sample in the present study. The sample was not balanced by gender and some have claimed gender to be important in aesthetic experience (Chattterjee \& Vartanian; 2014). Nevertheless, Smith and Smith (2001), Smith, Smith and Tinio (2017) and Tröndle, Krichberg and Tschacher (2014) found no evidence of an effect of gender on viewing time on paintings.

There are also a number of methodological issues that might be important to consider. First, our estimates of gaze ambiguity were determined from participant ratings. This seems appropriate given that what is of concern is our experience of gaze. Nevertheless, it might be that gaze should be measured more formally using geometrical analyses (e.g., see Todorović, 2006). Second, participants were given as long as they wished in which to rate their liking of paintings. The use of an unlimited viewing period was to simulate the conditions of picture 
inspection in a gallery context. It is possible that using a fixed viewing time might have led to different gaze behaviour. In the absence of actual data, we would hypothesise that truncating viewing time would increase the focus on faces, making the findings in relation to faces more extreme than those reported in the presented study (see Figure 4).

The viewing strategy of naïve participants suggests that they view portraits by focussing on faces with the context providing a gist. The data open up a range of questions about spectatorship by more expert viewers. Two questions in particular strike us as worthy of future study. First, is expertise manifest in focussed attention being allocated to contexts rather than being allocated to faces? If the answer to this question is "yes" then this suggests that experts have some ability to control and overcome more reflexive aspects of visual function when viewing paintings. In turn, if this is the case, then a second, follow-on, question pertains to whether there is a time-course to the allocation of attention to different aspects of the painting. For example, it seems at least possible that experts may initially allocate attention to faces, and only later transfer attentional resources to other aspects of the painting within the context. Exploration of these questions is beyond the scope of the present study but stating them provides a clear direction for future experiments investigating the influence of expertise on the spectatorship of portraiture. 


\section{Acknowledgements}

We thank Danita Mooney for help with data collection and Denis Drieghe for advise on eye movement data analysis.

\section{Ethics}

The University of Southampton research ethic committee granted ethical approval for this study. Informed consent form was provided by participants prior to participation in this study.

\section{Declaration of conflicting interests}

The authors declared no potential conflicts of interest with respect to the research, authorship, and/or publication of this article.

\section{Funding}

The first author is a fully funded studentship from the University of Southampton. The others authors received no financial support for the research, authorship and/or publication of this article. 


\section{References}

Baayen, R. H., Davidson, D. J., \& Bates, D. M. (2008). Mixed-effects modeling with crossed random effects for subjects and items. Journal of Memory and Language, 59(4), 390412. doi: $10.1016 /$ j.jml.2007.12.005

Baron- Cohen, S., Jolliffe, T., Mortimore, C., \& Robertson, M. (1997). Another advanced test of theory of mind: Evidence from very high functioning adults with autism or Asperger syndrome. Journal of Child Psychology and Psychiatry, 38(7), 813-822. doi: 10.1111/j.1469-7610.1997.tb01599.x

Bates, D., Mächler, M., Bolker, B. M., \& Walker, S. C. (2015). Fitting Linear Mixed- Effects Models using lme4. Journal of Statistical Software, 67(1), 1 - 48. doi: 10.18637/jss.v067.i01

Batki, A., Baron-Cohen, S., Wheelwright, S., Connellan, J., \& Ahluwalia, J. (2000). Is there an innate gaze module? Evidence from human neonates. Infant Behavior and Development, 23(2), 223-229. doi: 10.1016/S0163-6383(01)00037-6

Bentin, S., Allison, T., Puce, A., Perez, E., \& McCarthy, G. (1996). Electrophysiological studies of face perception in humans. Journal of Cognitive Neuroscience, 8(6), 551565. doi:10.1162/jocn.1996.8.6.551

Bindemann, M., \& Lewis, M. B. (2013). Face detection differs from categorization: Evidence from visual search in natural scenes. Psychonomic Bulletin \& Review, 20(6), 11401145. doi:10.3758/s13423-013-0445-9

Birmingham, E., Bischof, W. F., \& Kingstone, A. (2009). Saliency does not account for fixations to eyes within social scenes. Vision research, 49(24), 2992-3000. doi: 10.1016/j.visres.2009.09.014

Borji, A., \& Itti, L. (2014). Defending Yarbus: Eye movements reveal observers' task. Journal of Vision, 14(3). doi:10.1167/14.3.29 
Boyarskaya, E., Sebastian, A., Bauermann, T., Hecht, H., \& Tuscher, O. (2015). The Mona Lisa Effect: Neural Correlates of Centered and Off-Centered Gaze. Human Brain Mapping, 36(2), 619-632. doi:10.1002/hbm.22651

Bruce, V., \& Young, A. (1986). Understanding face recognition. British Journal of Psychology, 77(3), 305-327. doi: 10.1111/j.2044-8295.1986.tb02199.x

Brysbaert, M., \& Stevens, M. (2018). Power analysis and effect size in mixed effects models: a tutorial. Journal of Cognition, 1(1), 9, 1 - 20. doi: 10.5334/joc.10

Carlin, J. D., \& Calder, A. J. (2013). The neural basis of eye gaze processing. Current Opinion in Neurobiology, 23(3), 450-455. doi:10.1016/j.conb.2012.11.014

Castelhano, M. S., \& Henderson, J. M. (2008). The influence of color on the perception of scene gist. Journal of Experimental Psychology: Human Perception and Performance, 34(3), 660-675. doi:10.1037/0096-1523.34.3.660

Cerf, M., Frady, E. P., \& Koch, C. (2009). Faces and text attract gaze independent of the task: Experimental data and computer model. Journal of Vision, 9(12), 1-15. DOI: $10.1167 / 9.12 .1$

Charman, T., Baron-Cohen, S., Swettenham, J., Baird, G., Cox, A., \& Drew, A. (2000). Testing joint attention, imitation, and play as infancy precursors to language and theory of mind. Cognitive development, 15(4), 481-498. doi: 10.1016/S08852014(01)00037-5

Chatterjee, A., \& Vartanian, O. (2014). Neuroaesthetics. Trends in Cognitive Sciences, 18(7), 370-375. doi: 10.1016/j.tics.2014.03.003

Costa, M., \& Corazza, L. (2006). Aesthetic phenomena as supernormal stimuli: The case of eye, lip, and lower-face size and roundness in artistic portraits. Perception, 35(2), 229-246. doi: 10.1068/p3449 
Donnelly, N., Harland, B., Mestry, N., Thompson, N., Trawinski, T., \& Liversedge, S. P. (2017). The Influence of Pupil Alignment on Spectator Address in Manet's Portraiture. Psychology of Aesthetics Creativity and the Arts, 11(2), 167-178. doi:10.1037/aca0000096

Dupierrix, E., de Boisferon, A. H., Méary, D., Lee, K., Quinn, P. C., Di Giorgio, E., Simion, F., Tomonaga, M., \& Pascalis, O. (2014). Preference for human eyes in human infants. Journal of Experimental Child Psychology, 123, 138-146. doi: 10.1016/j.jecp.2013.12.010

Crary, J. (1992). Techniques of the Observer: On Vision and Modernity in the Nineteenth Century. Cambridge, Massachusetts, MIT press.

Fan, J., McCandliss, B. D., Sommer, T., Raz, A., \& Posner, M. I. (2002). Testing the efficiency and independence of attentional networks. Journal of Cognitive Neuroscience, 14(3), 340-347. doi:10.1162/089892902317361886

Fuchs, I., Ansorge, U., Redies, C., \& Leder, H. (2011). Salience in paintings: bottom-up influences on eye fixations. Cognitive Computation, 3(1), 25-36. doi:10.1007/s12559-010-9062-3

Fletcher-Watson, S., Findlay, J. M., Leekam, S. R., \& Benson, V. (2008). Rapid detection of person information in a naturalistic scene. Perception, 37(4), 571-583. doi:10.1068/p5705

Fried, M. (1996). Manet's modernism, or, the face of painting in the 1860s. Chicago, IL: The University of Chicago Press.

Fried, M. (1980). Absorption and theatricallity: Painting and beholder in the age of Diderot. Barkeley and Los Angeles, CA: The University of California Press. 
Frischen, A., Bayliss, A. P., \& Tipper, S. P. (2007). Gaze cueing of attention: visual attention, social cognition, and individual differences. Psychological Bulletin, 133(4), 694 724. doi: $10.1037 / 0033-2909.133 .4 .694$

Godijn, R., \& Theeuwes, J. (2004). The Relationship Between Inhibition of Return and Saccade Trajectory Deviations. Journal of Experimental Psychology: Human Perception and Performance, 30(3), 538-554. doi:10.1037/0096-1523.30.3.538

Godwin, H. J., Liversedge, S. P., Kirkby, J. A., Boardman, M., Cornes, K., \& Donnelly, N. (2015). The influence of experience upon information-sampling and decision-making behaviour during risk assessment in military personnel. Visual Cognition, 23(4), 415431. doi: 10.1080/13506285.2015.1030488

Gombrich, E. (1995). The Story about Art. London, Phaidon Press Limited.

Graham, D., Pallett, P. M., Meng, M., \& Leder, H. (2014). Representation and aesthetics of the human face in portraiture. Art \& Perception, 2(1-2), 75-98. doi: $10.1163 / 22134913-00002026$

Graham, D. J., \& Redies, C. (2010). Statistical regularities in art: Relations with visual coding and perception. Vision Research, 50(16), 1503-1509. doi:10.1016/j.visres.2010.05.002

Green, P. \& MacLeod, C. J. (2016). SIMR: An R package for power analysis of generalized linear mixed models by simulation. Methods in Ecology and Evolution 7(4): 493-498, doi: 10.1111/2041-210X.12504

Green, P., MacLeod, C. J., \& Alday, P. (2016). Package ‘simr', Available at: https://cran.rproject.org/web/packages/simr/simr.pdf

Harkness, J. A., \& Schoua-Glusberg, A. (1998). Questionnaires in translation. In: Harkness, J. (Ed.), Cross-cultural survey equivalence (pp. 87 - 126). Mannheim, ZUMANachrichten Spezial. 
Harland, B., Gillett, J., Mann, C. M., Kass, J., Godwin, H. J., Liversedge, S. P., \& Donnelly, N. (2014). Modes of address in pictorial art: An eye movement study of Manet's Bar at the Folies-Bergère. Leonardo, 47(3), 241-248. doi: 10.1162/LEON_a_00676

Haxby, J. V., Hoffman, E. A., \& Gobbini, M. I. (2000). The distributed human neural system for face perception. Trends in Cognitive Sciences, 4(6), 223-233. doi:10.1016/s13646613(00)01482-0

Hayn-Leichsenring, G. U., Kloth, N., Schweinberger, S. R., \& Redies, C. (2013). Adaptation effects to attractiveness of face photographs and art portraits are domain-specific. $i$ Perception, 4(5), 303-316. doi: 10.1068/i0583

Henderson, J. M., Shinkareva, S. V., Wang, J., Luke, S. G., \& Olejarczyk, J. (2013).

Predicting Cognitive State from Eye Movements. PLoS One, 8(5), 1-6. doi:10.1371/journal.pone.0064937

Humphrey, N. K., \& McManus, I. C. (1973). Status and the left cheek. New Scientist, 437439.

Itti, L., \& Koch, C. (2001). Computational modelling of visual attention. Nature Reviews Neuroscience, 2(3), 194-203. doi:10.1038/35058500

Jakesch, M., \& Leder, H. (2009). Finding meaning in art: Preferred levels of ambiguity in art appreciation. Quarterly Journal of Experimental Psychology, 62(11), 2105-2112. doi:10.1080/17470210903038974

Johnston, P., Molyneux, R., \& Young, A. W. (2015). The N170 observed 'in the wild': robust event-related potentials to faces in cluttered dynamic visual scenes. Social Cognitive and Affective Neuroscience, 10(7), 938-944. doi:10.1093/scan/nsu136

Kampis, D., Fogd, D., \& Kovács, Á. M. (2017). Nonverbal components of Theory of Mind in typical and atypical development. Infant Behavior and Development, 48, 54-62. doi: 10.1016/j.infbeh.2016.11.001 
Langton, S. R. H., Law, A. S., Burton, A. M., \& Schweinberger, S. R. (2008). Attention capture by faces. Cognition, 107(1), 330-342. doi:10.1016/j.cognition.2007.07.012

Locher, P., Krupinski, E., Mello-Thoms, C., \& Nodine, C. (2007). Visual interest in pictorial art during an aesthetic experience. Spatial Vision, 21(1-2), 55-77. doi:10.1163/156856808782713762

Massaro, D., Savazzi, F., Di Dio, C., Freedberg, D., Gallese, V., Gilli, G., \& Marchetti, A. (2012). When art moves the eyes: a behavioral and eye-tracking study. PLoS ONE, 7(5), 1 - 16. doi.org:10.1371/journal.pone.0037285

Oliva, A., \& Torralba, A. (2006). Building the gist of a scene: The role of global image features in recognition. Progress in Brain Research, 155(Part B), 23-36. doi: $10.1016 / \mathrm{S} 0079-6123(06) 55002-2$

Pippin, R. B. (2014). After the beautiful: Hegel and the philosophy of pictorial modernism. Chicago, IL: University of Chicago Press.

Rayner, K. (2009). The 35th Sir Frederick Bartlett Lecture: Eye movements and attention in reading, scene perception, and visual search. Quarterly Journal of Experimental Psychology, 62(8), 1457-1506. doi: 0.1080/17470210902816461

Reff, T. (1975). Manet's Portrait of Zola. The Burlington Magazine, 117(862), 34-44.

Savazzi, F., Massaro, D., Di Dio, C., Gallese, V., Gilli, G., \& Marchetti, A. (2014). Exploring responses to art in adolescence: a behavioral and eye-tracking study. PLoS ONE, 9(7), 1 -12. doi: 10.1371/journal.pone.0102888

Schirillo, J. A. (2007). Gender's effect on the hemispheric laterality of Rembrandt's portraits. Spatial Vision, 21(1), 19-26. doi: 10.1163/156856807782753859

Schmidt, B. K., Vogel, E. K., Woodman, G. F., \& Luck, S. J. (2002). Voluntary and automatic attentional control of visual working memory. Perception \& Psychophysics, 64(5), 754-763. doi: 10.3758/BF03194742 
Schulz, K., \& Hayn-Leichsenring, G. U. (2017). Face Attractiveness versus Artistic Beauty in Art Portraits: A Behavioral Study. Frontiers in Psychology, 8(2254), 1 - 9. doi: 10.3389/fpsyg.2017.02254

Senju, A., Csibra, G., \& Johnson, M. H. (2008). Understanding the referential nature of looking: Infants' preference for object-directed gaze. Cognition, 108(2), 303-319. doi: 10.1016/j.cognition.2008.02.009

Shackman, A. J., Sarinopoulos, I., Maxwell, J. S., Pizzagalli, D. A., Lavric, A., \& Davidson, R. J. (2006). Anxiety selectively disrupts visuospatial working memory. Emotion, 6(1), 40-61. doi:10.1037/1528-3542.6.1.40

Smith, J. K., \& Smith, L. F. (2001). Spending time on art. Empirical Studies of the Arts, 19, 229-236. doi: 10.2190/5MQM-59JH-X21R-JN5J

Smith, L. F., Smith, J. K., \& Tinio, P. P. (2017). Time spent viewing art and reading labels. Psychology of Aesthetics, Creativity, and the Arts, 11(1), 77 - 85. doi: $10.1037 / \mathrm{aca} 0000049$

Tatler, B. W., Brockmole, J. R., \& Carpenter, R. H. S. (2017). LATEST: A model of saccadic decisions in space and time. Psychological Review, 124(3), 267. doi: $10.1037 /$ rev0000054

Theeuwes, J., Belopolsky, A., \& Olivers, C. N. (2009). Interactions between working memory, attention and eye movements. Acta Psychologica, 132(2), 106-114. doi: 10.1016/j.actpsy.2009.01.005

Theeuwes, J., \& Van der Stigchel, S. (2006). Faces capture attention: Evidence from inhibition of return. Visual Cognition, 13(6), 657-665. doi: $10.1080 / 13506280500410949$

Todorović, D. (2009). The effect of face eccentricity on the perception of gaze direction. Perception, 38(1), 109-132. doi:10.1068/p5930 
Todorović, D. (2006). Geometrical basis of perception of gaze direction. Vision Research, 46(21), 3549-3562. doi:10.1016/j.visres.2006.04.011

Tröndle, M., Kirchberg, V., \& Tschacher, W. (2014). Subtle differences: Men and women and their art reception. Journal of Aesthetic Education, 48, 65-93.

Tyler, C. W. (1998). Painters centre one eye in portraits. Nature, 392(6679), 877-878. doi:10.1038/31833

Wolfe, J. M., Võ, M. L. H., Evans, K. K., \& Greene, M. R. (2011). Visual search in scenes involves selective and nonselective pathways. Trends in Cognitive Sciences, 15(2), 77-84. doi: 10.1016/j.tics.2010.12.001

Valenza, E., Simion, F., Cassia, V. M., \& Umiltà, C. (1996). Face preference at birth. Journal of Experimental Psychology: Human Perception and Performance, 22(4), 892 - 903. doi:10.1037/0096-1523.22.4.892

Venables, W. N. \& Ripley, B. D. (2002). Modern Applied Statistics with S. Fourth Edition. New York: Springer

Villani, D., Morganti, F., Cipresso, P., Ruggi, S., Riva, G., \& Gilli, G. (2015). Visual exploration patterns of human figures in action: an eye tracker study with art paintings. Frontiers in Psychology, 6(1636), 1 - 10. doi: 10.3389/fpsyg.2015.01636

Yarbus, A. L. (1967). Eye movements during perception of complex objects. Springer.

Young, A. W. (2018). Faces, people and the brain: The 45th Sir Frederic Bartlett Lecture. Quarterly Journal of Experimental Psychology, 71(3), 569 - 594. doi: $10.1177 / 1747021817740275$

Zhao, Q., \& Koch, C. (2011). Learning a saliency map using fixated locations in natural scenes. Journal of Vision, 11(3), 1-5. doi: 10.1167/11.3.1 
Table 1

List of all portraits used in experiment collapsed by authors, number of salient features in the context, and also the mean categorization gaze rating and number of ROIs in Face and Body ROIs.

Artists and painting
Year Saliency Gaze ROIs

category Face(s);

Bodies

Manet

Spanish Singer

1860

1.5

$1 ; 1$

Boy With Cherries

1860

2.31

$1 ; 1$

Madam Brunet

1860

2

1.81

$1 ; 1$

Nymph Surprised

186

Boy With a Dog

1861

3

1.31

$1 ; 1$

Boy With the Sword

1861

Gypsy With Cigarette

1862

2

1.5

$1 ; 1$

Lola de Valenca

1862

0

1.38

$1 ; 1$

Victorine Meurent

1862

5

2.44

$1 ; 1$

Mlle Victorine in the Costume of an Espada

1

$1.38 \quad 1 ; 1$

Street Singer

Young Woman Reclining in Spanish Costume

Young Man in the Costume of a Majo

3

1.56

$1 ; 1$

Head of Christ

The Tragic Actor

Beggar With Duffle Coat

1862

1862

1863

1863

$1864 \quad 0 \quad 2.38 \quad 1 ; 1$

1865

3

$1.44 \quad 1 ; 1$

$1.69 \quad 3 ; 3$

$1.81 \quad 1 ; 1$

$2.93 \quad 1 ; 1$

$1.75 \quad 1 ; 1$

$1865 \quad 0 \quad 1.94 \quad 1 ; 1$




\begin{tabular}{|c|c|c|c|c|}
\hline Angelina & 1865 & 0 & 2.81 & $1 ; 1$ \\
\hline The Fifer & 1866 & 4 & 1.88 & $1 ; 1$ \\
\hline Zacharie Astruc & 1866 & 5 & 1.44 & $2 ; 2$ \\
\hline The Philosopher & 1866 & 3 & 1.94 & $1 ; 1$ \\
\hline Young Lady With Parrot & 1866 & 1 & 1.88 & $1 ; 1$ \\
\hline The Lecture (Manet's wife) & 1866 & 10 & 2.44 & $2 ; 2$ \\
\hline Soap Bubbles & 1867 & 3 & 1.69 & $1 ; 1$ \\
\hline Emile Zola & 1868 & 7 & 1.63 & $1 ; 1$ \\
\hline Young Man Peeling a Pear & 1868 & 1 & 3.19 & $1 ; 1$ \\
\hline Theodore Duret & 1868 & 5 & 2.13 & $1 ; 1$ \\
\hline Eva Gonzales & 1870 & 2 & 2.63 & $1 ; 1$ \\
\hline In the Garden & 1870 & 5 & 3.19 & $3 ; 3$ \\
\hline Repose: Berthe Morisot & 1870 & 3 & 2.25 & $1 ; 1$ \\
\hline Suzanne Manet & 1870 & 0 & 2.5 & $1 ; 1$ \\
\hline Monsieur Tillet & 1871 & 0 & 1.94 & $1 ; 1$ \\
\hline Berthe Morisot Holding a Bunch of Violets & 1872 & 2 & 1.31 & $1 ; 1$ \\
\hline Berthe Morisot Reclining & 1872 & 0 & 2.81 & $1 ; 1$ \\
\hline The Brunette With Bare Breasts & 1872 & 0 & 3.13 & $1 ; 1$ \\
\hline Veiled Young Woman & 1872 & 0 & 3.88 & $1 ; 1$ \\
\hline Woman With Fans & 1873 & 5 & 2.31 & $1 ; 1$ \\
\hline Gare Saint Lazare & 1873 & 6 & 1.75 & $2 ; 2$ \\
\hline Le Bon Bock & 1873 & 0 & .81 & $1 ; 1$ \\
\hline Margaite de Conflanins Wearing a Hood & 1873 & 5 & 3.38 & $1 ; 1$ \\
\hline Berthe Morisot With Fan & 1874 & 5 & 2 & $1 ; 1$ \\
\hline Berthe Morisot With Hat, in Mourning & 1874 & 1 & 3.56 & $1 ; 1$ \\
\hline
\end{tabular}


Young Woman With a Book

Gilbert Marcellin Desboutin

Woman With Umbrella

Stephane Mallarme

Nana

Antonin Proust, Study

The Plum

Faure as Hamlet

Self Portrait With a Palette

Le Journal Illustre

Self Portrait With Skull Cap

Lady With a Black Fichu

Marguerite Gauthier

Lina Campineanu

Monsieur Brun

Madame Manet in the Conservatory

Woman With a Gold Pin

Isabelle Lemonnier (Jeane Femme en Robe du

Bal)

Emilie Ambre in the Role of Carmen

Isabelle Lemonnier with White Scarf

Corner of the Café Concert

Isabelle Lemonnier

Antonin Proust

The Promenade

\begin{tabular}{|c|c|c|}
\hline 1875 & 4 & 2.38 \\
\hline 1875 & 3 & 2.25 \\
\hline 1875 & 3 & 2.5 \\
\hline 1876 & 5 & 3.25 \\
\hline 1877 & 5 & 1.56 \\
\hline 1877 & 0 & 1.81 \\
\hline 1877 & 6 & 2.38 \\
\hline 1877 & 0 & 2.13 \\
\hline 1878 & 1 & 1.75 \\
\hline 1878 & 8 & 2.81 \\
\hline 1878 & 1 & 1.88 \\
\hline 1878 & 3 & 2.69 \\
\hline 1878 & 2 & 3 \\
\hline 1878 & 3 & 2.44 \\
\hline 1879 & 1 & 1.69 \\
\hline 1879 & 11 & 1.19 \\
\hline 1879 & 3 & 2.69 \\
\hline 1879 & 0 & 2.63 \\
\hline
\end{tabular}

1879

1879

1880

1880

1880

1880

; 1

; 1

; 1

; 1

$2 ; 2$

$1 ; 1$

; 1

; 1

; 1

; 1

; 1

; 1

; 1

; 1

; 1

; 1

; 1

; 1 
Isabelle Lemonnier With a Muff

1880

2.13

$1 ; 1$

Pertuiset, Lion Hunter

1881

2.56

$1 ; 1$

Henry Bernstein as a Child

1881

4

88

$1 ; 1$

Henri Rochefort

1881

1882

2

1.5

$1 ; 1$

Head of Jean Baptiste Faure

1882

0

3.31

$1 ; 1$

Courbet

\begin{tabular}{|c|c|c|c|c|}
\hline Portrait of a Spanish Lady & 1855 & 3 & 2.25 & $1 ; 1$ \\
\hline Portrait of Jules Valles & 1865 & 0 & .81 & $1 ; 1$ \\
\hline Portrait of Juliette Courbet & 1844 & 5 & 1.69 & $1 ; 1$ \\
\hline Portrait of Pierre Joseph Proudhon (1865) & 1865 & 0 & 2.38 & $1 ; 1$ \\
\hline Portrait of Chenavard & 1869 & 1 & 2.13 & $1 ; 1$ \\
\hline Self-Portrait (Man with Pipe) & 1848 & 1 & 2.19 & $1 ; 1$ \\
\hline Portrait of H. J. van Wisselingh & 1846 & 1 & 2.25 & $1 ; 1$ \\
\hline Portrait of Pierre Joseph Proudhon (1853) & 1853 & 5 & 1.38 & $3 ; 3$ \\
\hline Portrait of Mlle. Jacquet & 1857 & 0 & 1.44 & $1 ; 1$ \\
\hline Jo, la Belle Irlandaise & 1866 & 0 & 2.5 & $1 ; 1$ \\
\hline The Cellist, self-portrait & 1847 & 0 & 1.25 & $1 ; 1$ \\
\hline Portrait of Paul Verlaine & 1871 & 0 & 1.19 & $1 ; 1$ \\
\hline Self-Portrait (The Wounded Man) & 1854 & 1 & 2.19 & $1 ; 1$ \\
\hline The Village Girl With A Goatling & 1860 & 0 & 3.38 & $1 ; 1$ \\
\hline A Young Woman Reading & 1866 & 10 & 1.31 & $1 ; 1$ \\
\hline Portrait of Zelie Courbet & 1842 & 4 & 1.5 & $1 ; 1$ \\
\hline Young Man in a Landscape & 1845 & 4 & 2.06 & $1 ; 1$ \\
\hline Portrait of Alfred Bruyas & 1854 & 3 & 1.88 & $1 ; 1$ \\
\hline Portrait of Gabrielle Borreau (The Dreamer) & 1862 & 4 & 3 & $1 ; 1$ \\
\hline
\end{tabular}


Proudhon and His Children

Self-Portrait (Man with Leather Belt)

The Desperate Man

Self-Portrait (Courbet with Black Dog)

Louis Gueymard (1822-1880) as Robert le Diable

Gypsy in Reflection

The Young Bather

Portrait of Charles Baudelaire

Woman with Garland

The Sleepwalker

Portrait of Young Woman in the style of Labille-

Guiard

Portrait of a Young Girl from Salins

Portrait of Madame Proudhon

Portrait of a Woman

Woman of Frankfurt

Madame Mere Gregoire

The Young Lady on the Banks of the Seine
1853

1880

1843

1844

1857

1869

1866

1848

1856

1865

c. 1866

1860

1865

1850

1858

1856

1857

1859

1882

1890

1870

1882

1886

1

1.81

$1 ; 1$

1.44

$1 ; 1$

0

.94

$1 ; 1$

3

1.44

$1 ; 1$

4

$1.75 \quad 3 ; 3$

0

$1.69 \quad 1 ; 1$

$2.25 \quad 1 ; 1$

1.19

$1 ; 1$

4

2.56

$1 ; 1$

10

$1.75 \quad 1 ; 1$

.81

$1 ; 1$

Fantin-Latour

Self-Portrait (1859)

Charlotte Dubourg

Portrait of Sonia

A Leitura

Portrait of Madame Leon Maitre

Portrait of Leon Maitre 


\begin{tabular}{|c|c|c|c|c|}
\hline Portrait of Eduouard Manet & 1867 & 0 & 1.44 & $1 ; 1$ \\
\hline Madeleine Lerolle & 1882 & 7 & 1.56 & $1 ; 1$ \\
\hline Mademoiselle de Fitz James & 1867 & 0 & 1.19 & $1 ; 1$ \\
\hline Self-Portrait (1867) & 1867 & 0 & 1.25 & $1 ; 1$ \\
\hline Portrait of James McNeil Whistler & 1865 & 0 & 1.13 & $1 ; 1$ \\
\hline Portrait of a Woman & 1885 & 0 & 1.25 & $1 ; 1$ \\
\hline Self Portrait (1858) & 1858 & 0 & 2.56 & $1 ; 1$ \\
\hline Bathsheba & 1903 & 5 & 2.31 & $1 ; 1$ \\
\hline Portrait of Eva Callimachi-Catargi & 1881 & 0 & 2.63 & $1 ; 1$ \\
\hline Young Lady Reading & c. 1890 & 6 & 2.44 & $1 ; 1$ \\
\hline Portrait of a Man & c. 1871 & 0 & 1.31 & $1 ; 1$ \\
\hline The Reader & 1861 & 2 & .93 & $1 ; 1$ \\
\hline Portrait of Ruth Edwards & 1864 & 2 & 1.44 & $1 ; 1$ \\
\hline Head of a Young Girl & 1870 & 0 & 1.19 & $1 ; 1$ \\
\hline Portrait of Mrs. Madeleine Burty Haviland & 1893 & 0 & 1.75 & $1 ; 1$ \\
\hline Adolphe Jullien & 1887 & 2 & .81 & $1 ; 1$ \\
\hline Self Portrait (1861) & 1861 & 4 & 1.94 & $1 ; 1$ \\
\hline Reveil de Venus & 1903 & 8 & 2.44 & $1 ; 1$ \\
\hline Victoria Dubourg & 1873 & 2 & .81 & $1 ; 1$ \\
\hline Madame Leopold Gravier & 1889 & 3 & 1.06 & $1 ; 1$ \\
\hline Reclining Nude & 1892 & 0 & 2.06 & $1 ; 1$ \\
\hline Portrait of Mademoiselle Marie Fantin-Latour & 1859 & 0 & .94 & $1 ; 1$ \\
\hline Mr and Mrs Edwin Edwards & 1875 & 0 & 1.5 & $2 ; 2$ \\
\hline Immortality & 1889 & 4 & 1.56 & $1 ; 1$ \\
\hline Drawing Lesson & 1879 & 6 & 1.94 & $2 ; 2$ \\
\hline
\end{tabular}


Woman at Her Toilette

$\begin{array}{cccc}1898 & 2 & 1.75 & 2 ; 2 \\ 1883 & 3 & 1 & 1 ; 1\end{array}$

Danaé

$\begin{array}{llll}\text { c. } 1904 & 4 & 2.13 & 2 ; 2\end{array}$

The Two Sisters

1859

4

$2.19 \quad 2 ; 2$

Venus and Cupid

1902

7

$3.44 \quad 2 ; 2$

Note. In third column is shown number of salient regions in the context. Gaze categories $(0=$ unambiguous, 5 = completely ambiguous) are shown in Column 4. 
Table 2

Fixed effect estimates from the Linear Mixed Models for normalised number of fixations and mean fixation duration on type of ROIs.

\begin{tabular}{|c|c|c|c|c|c|c|}
\hline & \multicolumn{3}{|c|}{ Fixations } & \multicolumn{3}{|c|}{ Mean fixation duration (ms) } \\
\hline & $b$ & $S E$ & $t$ & $b$ & $S E$ & $t$ \\
\hline Intercept & 39.15 & 1.11 & 10.77 & 330.78 & 5.46 & 60.63 \\
\hline Body & -31.89 & 0.58 & -55.47 & -79.18 & 3.24 & - 24.43 \\
\hline Context & -39.01 & 0.58 & -67.85 & -171.38 & 3.24 & -52.88 \\
\hline
\end{tabular}

Note. Eye movement made to face ROIs was treated as the baseline. Significant effects are indicated in bold.

Table 3

Mean (and Standard Deviation) Eye Movement Measures for each ROIs area as a function of type of sitter's Gaze and Saliency in the context.

\section{Gaze} Saliency

\begin{tabular}{rccccc}
\hline Number of fixations & Focused & Ambiguous & & Salient & No-salient \\
\cline { 2 - 3 } \cline { 5 - 6 } Face & $7.20(5.66)$ & $7.48(6.24)$ & & $7.48(6.08)$ & $7.15(5.92)$ \\
Body & $7.21(7.30)$ & $7.30(7.14)$ & & $7.35(7.22)$ & $7.06(7.13)$ \\
Context & $2.77(5.26)$ & $2.62(4.36)$ & & $2.66(4.81)$ & $2.72(4.43)$
\end{tabular}

Mean fixation duration (ms)

$\begin{array}{rrrrr}\text { Face } & 332.00(124.05) & 330.10(120.62) & 332.20(123.30) & 327.30(118.19) \\ \text { Body } & 250.08(125.84) & 252.45(127.69) & 250.72(125.93) & 253.78(129.69) \\ \text { Context } & 163.91(159.113) & 156.87(154.55) & 160.23(156.79) & 157.35(154.89)\end{array}$

Note. The mean and standard deviation is calculated across participants. 
Table 4

Fixed effect estimates from the Generalized Linear Mixed Models for binominal transformed number of fixations and mean fixation duration on type of gaze and salient condition.

\begin{tabular}{|c|c|c|c|c|c|c|}
\hline \multirow[b]{2}{*}{ Fixations } & \multicolumn{3}{|c|}{ Body } & \multicolumn{3}{|c|}{ Context } \\
\hline & $b$ & $S E$ & $z$ & $b$ & $S E$ & $z$ \\
\hline Intercept & 3.20 & 0.30 & 10.77 & 0.51 & 0.16 & 3.24 \\
\hline Gaze & -0.17 & 0.25 & -0.68 & 0.05 & 0.08 & 0.62 \\
\hline Saliency & -0.03 & 0.25 & -0.12 & 0.07 & 0.08 & 0.85 \\
\hline Gaze*Saliency & -0.29 & 0.33 & -0.88 & 0.22 & 0.17 & 1.33 \\
\hline \multicolumn{7}{|c|}{ Mean fixation duration (ms) } \\
\hline Intercept & 3.17 & 0.31 & 10.38 & 0.44 & 0.16 & 2.77 \\
\hline Gaze & -0.11 & 0.23 & -0.49 & 0.05 & 0.08 & 0.62 \\
\hline Saliency & -0.21 & 0.17 & -1.23 & 0.07 & 0.08 & 0.86 \\
\hline Gaze*Saliency & -0.29 & 0.34 & -0.86 & 0.22 & 0.17 & 1.33 \\
\hline
\end{tabular}

Note. Ambiguous gaze with non-salient features in the context was treated as the baseline.

Significant effects are indicated in bold. 
Table 5

Fixed effect estimates from the Linear Mixed Models for log-transformed and normalised number of fixations and mean fixation duration on type of gaze and salient condition.

\begin{tabular}{|c|c|c|c|c|c|c|c|c|c|}
\hline & \multicolumn{3}{|c|}{ Face } & \multicolumn{3}{|c|}{ Body } & \multicolumn{3}{|c|}{ Context } \\
\hline Fixations & $b$ & $S E$ & $t$ & $b$ & $S E$ & $t$ & $b$ & $S E$ & $t$ \\
\hline Intercept & 3.10 & 0.08 & 36.56 & 1.80 & 0.04 & 42.16 & -1.70 & 0.03 & -49.8 \\
\hline Gaze & 0.02 & 0.15 & 0.12 & -0.10 & 0.07 & -1.35 & -0.01 & 0.04 & 0.31 \\
\hline Saliency & 0.62 & 0.15 & 4.21 & 0.08 & 0.07 & 1.17 & -0.09 & 0.04 & -2.36 \\
\hline Gaze*Saliency & 0.01 & 0.30 & 0.05 & 0.11 & 0.14 & 0.75 & 0.04 & 0.07 & 0.54 \\
\hline \multicolumn{10}{|c|}{ Mean fixation duration (ms) } \\
\hline Intercept & 5.77 & 0.02 & 243.35 & 5.55 & 0.02 & 279.17 & 5.52 & 0.02 & 261.9 \\
\hline Gaze & -0.01 & 0.01 & -0.42 & 0.00 & 0.01 & .84 & 0.02 & 0.02 & 0.84 \\
\hline Saliency & 0.02 & 0.01 & 1.65 & 0.01 & 0.01 & .67 & -0.01 & 0.02 & -0.74 \\
\hline Gaze*Saliency & 0.05 & 0.02 & 2.27 & 0.03 & 0.03 & .89 & -0.04 & 0.04 & .31 \\
\hline
\end{tabular}

Note. Ambiguous gaze with non-salient features /in the context was treated as the baseline. Significant effects are indicated in bold. 


\section{Running head: SPECTATORSHIP OF PORTRAITS}

Table 6

Means, standard deviations, and Pearson's r correlations with confidence intervals between eye movement measures for each ROI, salient features in the context, and participants' mean liking rating to each portrait $(N=142)$.

\begin{tabular}{|c|c|c|c|c|c|c|c|c|c|}
\hline Variable & $M$ & $S D$ & 1 & 2 & 3 & 4 & 5 & 6 & 7 \\
\hline 1. FixFace & 40.16 & 35.27 & & & & & & & \\
\hline 2. FixBody & 7.09 & 3.18 & $\begin{array}{c}.47 * * \\
{[.33, .59]}\end{array}$ & & & & & & \\
\hline 3. FixContext & 0.14 & 0.03 & $\begin{array}{c}-.10 \\
{[-.26, .06]}\end{array}$ & $\begin{array}{c}-.06 \\
{[-.23, .10]}\end{array}$ & & & & & \\
\hline 4. FixDurFace & 330.78 & 23.08 & $\begin{array}{c}.08 \\
{[-.09, .24]}\end{array}$ & $\begin{array}{c}-.10 \\
{[-.26, .07]}\end{array}$ & $\begin{array}{c}.02 \\
{[-.15, .18]}\end{array}$ & & & & \\
\hline 5. FixDurBody & 251.60 & 26.91 & $\begin{array}{c}-.07 \\
{[-.23, .10]}\end{array}$ & $\begin{array}{c}.11 \\
{[-.05, .27]}\end{array}$ & $\begin{array}{c}-.19 * \\
{[-.34,-} \\
.02]\end{array}$ & $\begin{array}{c}.06 \\
{[-.10, .23]}\end{array}$ & & & \\
\hline 6. FixDurCotext & 159.40 & 30.82 & $\begin{array}{c}-.03 \\
{[-.20, .13]}\end{array}$ & $\begin{array}{c}-.05 \\
{[-.21, .12]}\end{array}$ & $\begin{array}{c}.49 * * \\
{[.35, .61]}\end{array}$ & $\begin{array}{c}-.06 \\
{[-.22, .11]}\end{array}$ & $\begin{array}{c}-.05 \\
{[-.21, .11]}\end{array}$ & & \\
\hline 7. LJ & 2.33 & 0.32 & $\begin{array}{c}.23 * * \\
{[.07, .38]}\end{array}$ & $\begin{array}{c}-.05 \\
{[-.21, .12]}\end{array}$ & $\begin{array}{c}-.02 \\
{[-.19, .14]}\end{array}$ & $\begin{array}{c}.01 \\
{[-.15, .18]}\end{array}$ & $\begin{array}{c}.01 \\
{[-.15, .18]}\end{array}$ & $\begin{array}{c}.05 \\
{[-.12, .21]}\end{array}$ & \\
\hline 8. SF & 2.50 & 2.50 & $\begin{array}{c}.45^{* *} \\
{[.31, .58]}\end{array}$ & $\begin{array}{c}.35^{* *} \\
{[.20, .49]}\end{array}$ & $\begin{array}{c}-.08 \\
{[-.24, .08]}\end{array}$ & $\begin{array}{c}.15 \\
{[-.01, .31]}\end{array}$ & $\begin{array}{c}-.05 \\
{[-.21, .12]}\end{array}$ & $\begin{array}{c}-.08 \\
{[-.24, .08]}\end{array}$ & $\begin{array}{c}.23 * * \\
{[.07, .38]}\end{array}$ \\
\hline
\end{tabular}


Note. $*$ indicates $p<.05 ; * *$ indicates $p<.01 . M$ and $S D$ are used to represent mean and standard deviation, respectively. Values in square brackets indicate the $95 \%$ confidence interval for each correlation. FixFace - mean normalised number of fixations for face ROIs; FixBody mean normalised number of fixations for body ROIs; FixContext - mean normalised number of fixations for context ROIs; FixDurFace - mean fixations duration for face ROIs; FixDurBody - mean fixations duration for body ROIs; FixDurContext - mean fixations duration for context ROIs; LJ - participants' mean liking judgement SF - number of salient features in the context. 
Table 7

Means, standard deviations, and Pearson's $r$ correlations with confidence intervals between mean normalised number of fixations for each ROI with participants' scores in the battery of cognition tests $(N=24)$.

\begin{tabular}{|c|c|c|c|c|c|c|c|c|c|}
\hline Variable & $M$ & $S D$ & 1 & 2 & 3 & 4 & 5 & 6 & 7 \\
\hline 1. FixFace & 40.17 & 6.99 & & & & & & & \\
\hline 2. FixBody & 7.09 & 1.15 & $\begin{array}{c}-.91 * * \\
{[-.96,-.80]}\end{array}$ & & & & & & \\
\hline 3. FixContext & 0.14 & 0.04 & $\begin{array}{c}-.66^{* *} \\
{[-.84,-.35]}\end{array}$ & $\begin{array}{c}.34 \\
{[-.07, .66]}\end{array}$ & & & & & \\
\hline 4. ATN: ORIENT & 23.21 & 66.84 & $\begin{array}{c}-.13 \\
{[-.51, .28]}\end{array}$ & $\begin{array}{c}-.08 \\
{[-.46, .34]}\end{array}$ & $\begin{array}{c}.45^{*} \\
{[.05, .72]}\end{array}$ & & & & \\
\hline 5. ATN: ALERT & 25.19 & 34.57 & $\begin{array}{c}.10 \\
{[-.32, .48]}\end{array}$ & $\begin{array}{c}-.10 \\
{[-.48, .32]}\end{array}$ & $\begin{array}{c}.01 \\
{[-.39, .41]}\end{array}$ & $\begin{array}{c}.02 \\
{[-.39, .42]}\end{array}$ & & & \\
\hline 6. ATN: EXEC & 67.49 & 45.94 & $\begin{array}{c}-.09 \\
{[-.47, .33]}\end{array}$ & $\begin{array}{c}-.05 \\
{[-.44, .37]}\end{array}$ & {$\left[\begin{array}{c}.11 \\
{[-.30, .49]}\end{array}\right.$} & $\begin{array}{c}.22 \\
{[-.20, .57]}\end{array}$ & $\begin{array}{c}.30 \\
{[-.12, .63]}\end{array}$ & & \\
\hline $\begin{array}{l}\text { 7. 3-BACK: } \\
\text { SPATIAL }\end{array}$ & 40.62 & 24.98 & $\begin{array}{c}.48^{*} \\
{[.09, .74]}\end{array}$ & $\begin{array}{c}-.58 * * \\
{[-.80,-.23]}\end{array}$ & $\begin{array}{c}-.17 \\
{[-.53, .25]}\end{array}$ & $\begin{array}{c}.06 \\
{[-.35, .46]}\end{array}$ & $\begin{array}{c}.10 \\
{[-.31, .49]}\end{array}$ & $\begin{array}{c}.16 \\
{[-.26, .53]}\end{array}$ & \\
\hline $\begin{array}{l}\text { 8. 3-BACK: } \\
\text { VERBAL }\end{array}$ & 48.50 & 28.33 & .39 & $-.48 *$ & -.18 & .08 & .06 & .14 & $.87 * *$ \\
\hline
\end{tabular}




$$
[-.01, .69] \quad[-.74,-.09] \quad[-.54, .24] \quad[-.34, .47] \quad[-.35, .46] \quad[-.28, .52] \quad[.71, .94]
$$

Note. * indicates $p<.05 ; * *$ indicates $p<.01 . M$ and $S D$ are used to represent mean and standard deviation, respectively. Values in square brackets indicate the $95 \%$ confidence interval for each correlation. FixFace - mean normalised number of fixations for face ROIs; FixBody mean normalised number of fixations for body ROIs; FixContext - mean normalised number of fixations for context ROIs; ATN: ORIENT orienting component of the Attention Network Test; ATN: ALERT - alerting component of the Attention Network Test; ATN: EXEC executive component of the Attention Network Test; 3-BACK: SPATIAL - visuospatial version of 3 - back task; 3-BACK: VERBAL - verbal version of 3 - back task. 
Table 8

Means, standard deviations, and Pearson's $r$ correlations with confidence intervals between mean fixations duration for each ROI with participants' scores in the battery of cognition tests $(N=24)$.

\begin{tabular}{|c|c|c|c|c|c|c|c|c|c|}
\hline Variable & $M$ & $S D$ & 1 & 2 & 3 & 4 & 5 & 6 & 7 \\
\hline 1. FixDurFace & 330.78 & 40.46 & & & & & & & \\
\hline 2. FixDurBody & 251.60 & 32.83 & $\begin{array}{c}-.20 \\
{[-.56, .22]}\end{array}$ & & & & & & \\
\hline 3. FixDurCotext & 159.40 & 50.04 & $\begin{array}{c}-.16 \\
{[-.53, .26]}\end{array}$ & $\begin{array}{c}.50^{*} \\
{[.12, .75]}\end{array}$ & & & & & \\
\hline 4. ATN: ORIENT & 23.21 & 66.84 & $\begin{array}{c}.13 \\
{[-.29, .51]}\end{array}$ & $\begin{array}{c}.35 \\
{[-.06, .66]}\end{array}$ & $\begin{array}{c}.38 \\
{[-.02, .68]}\end{array}$ & & & & \\
\hline 5. ATN: ALERT & 25.19 & 34.57 & $\begin{array}{c}.27 \\
{[-.15, .61]}\end{array}$ & $\begin{array}{c}-.14 \\
{[-.51, .28]}\end{array}$ & $\begin{array}{c}.12 \\
{[-.30, .50]}\end{array}$ & $\begin{array}{c}.02 \\
{[-.39, .42]}\end{array}$ & & & \\
\hline 6. ATN: EXEC & 67.49 & 45.94 & $\begin{array}{c}.36 \\
{[-.05, .66]}\end{array}$ & $\begin{array}{c}.06 \\
{[-.35, .45]}\end{array}$ & $\begin{array}{c}.27 \\
{[-.15, .61]}\end{array}$ & $\begin{array}{c}.22 \\
{[-.20, .57]}\end{array}$ & $\begin{array}{c}.30 \\
{[-.12, .63]}\end{array}$ & & \\
\hline $\begin{array}{l}\text { 7. 3-BACK: } \\
\text { SPATIAL }\end{array}$ & 40.62 & 24.98 & $\begin{array}{c}.14 \\
{[-.28, .51]}\end{array}$ & $\begin{array}{c}-.25 \\
{[-.59, .17]}\end{array}$ & $\begin{array}{c}-.24 \\
{[-.59, .18]}\end{array}$ & $\begin{array}{c}.06 \\
{[-.35, .46]}\end{array}$ & $\begin{array}{c}.10 \\
{[-.31, .49]}\end{array}$ & $\begin{array}{c}.16 \\
{[-.26, .53]}\end{array}$ & \\
\hline $\begin{array}{l}\text { 8. 3-BACK: } \\
\text { VERBAL }\end{array}$ & 48.50 & 28.33 & .01 & -.27 & -.20 & .08 & .06 & .14 & $.87 * *$ \\
\hline
\end{tabular}




$$
[-.39, .42] \quad[-.61, .15] \quad[-.56, .22] \quad[-.34, .47] \quad[-.35, .46] \quad[-.28, .52] \quad[.71, .94]
$$

Note. * indicates $p<.05 ; * *$ indicates $p<.01 . M$ and $S D$ are used to represent mean and standard deviation, respectively. Values in square brackets indicate the $95 \%$ confidence interval for each correlation. FixDurFace - mean fixations duration for face ROIs; FixDurBody - mean fixations duration for body ROIs; FixDurContext - mean fixations duration for context ROIs; ATN: ORIENT - orienting component of the Attention Network Test; ATN: ALERT - alerting component of the Attention Network Test; ATN: EXEC -executive component of the Attention Network Test; 3-BACK: SPATIAL - visuospatial version of 3 - back task; 3-BACK: VERBAL - verbal version of 3 - back task. 

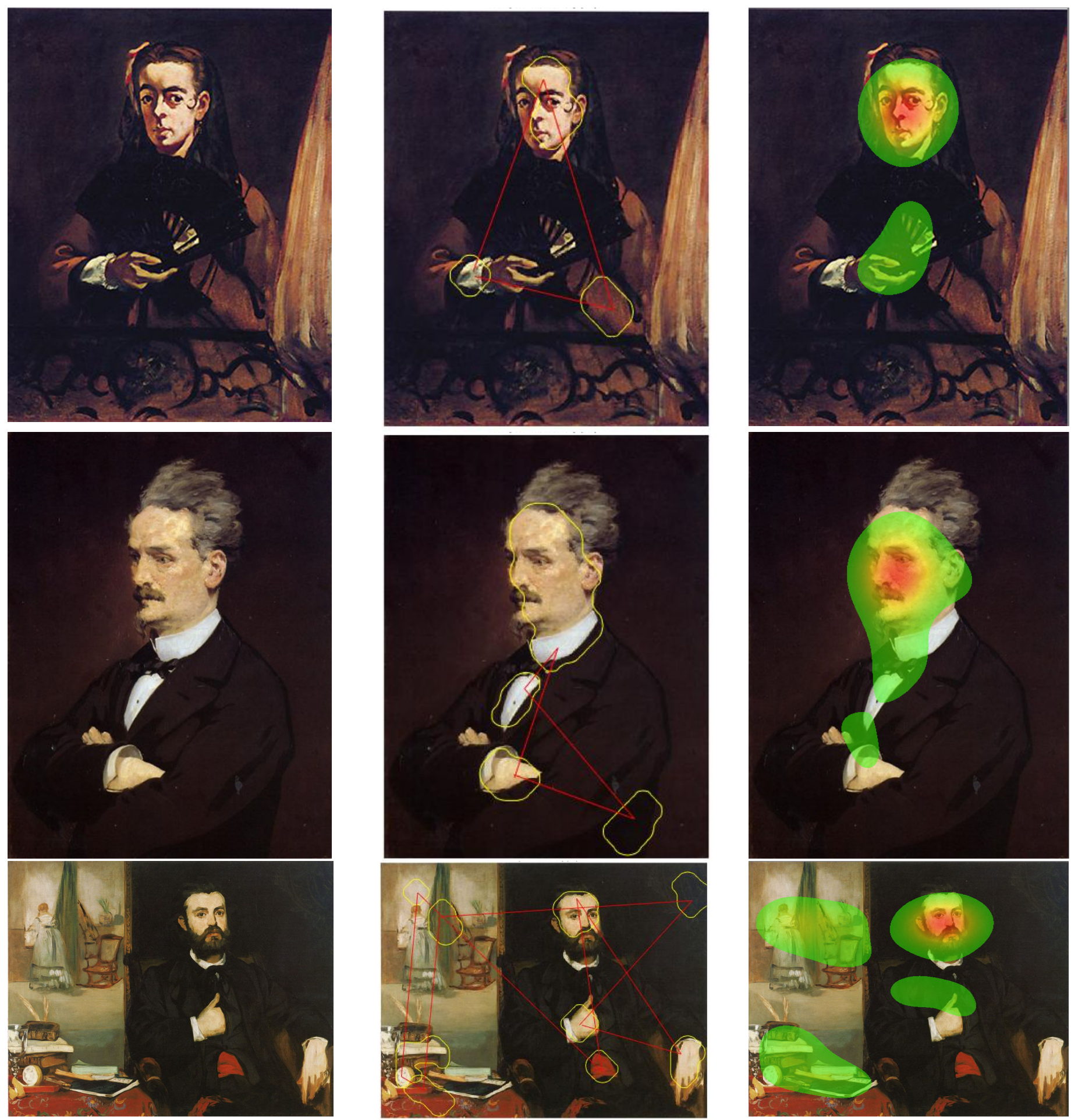

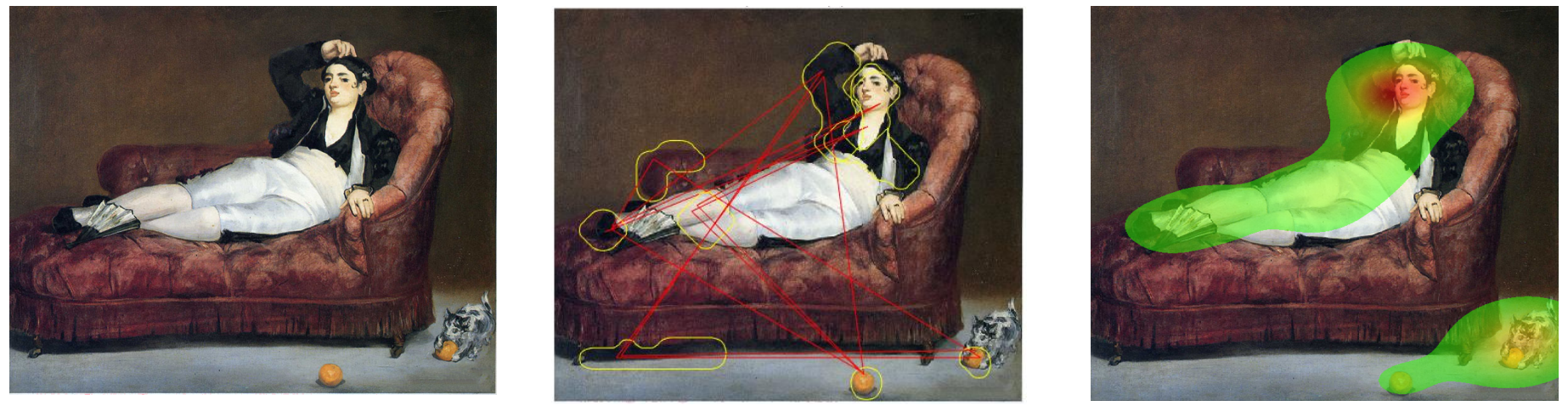

Figure 1. Examples of portraits used in the study with salient features indicated by Itti and Koch (2001) algorithm and heat maps grouped by gaze and saliency. First row: Manet, Angelina (1865; non-salient context and ambiguous gaze). Second row: Manet, Henri Rochefort (1881; non-salient context and focused gaze). Third row: Manet, Zacharie Astruc (1866; salient context and focused gaze). Fourth row: Manet, Young Woman Reclining in Spanish Costume (1863; salient context and ambiguous gaze). 

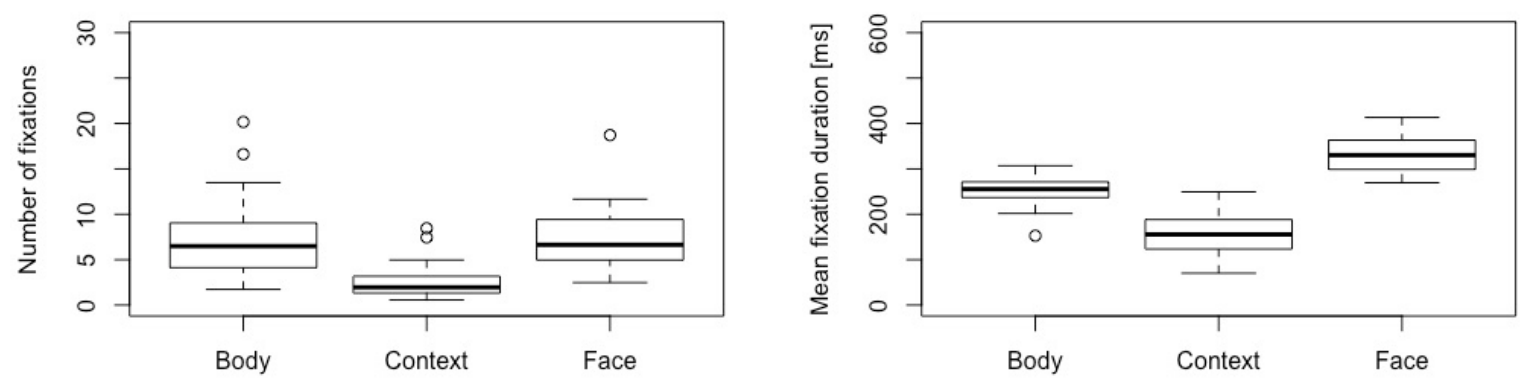

Figure 2. Boxplot for mean number of fixations and mean fixation durations for Body, Context, and Face ROIs. 


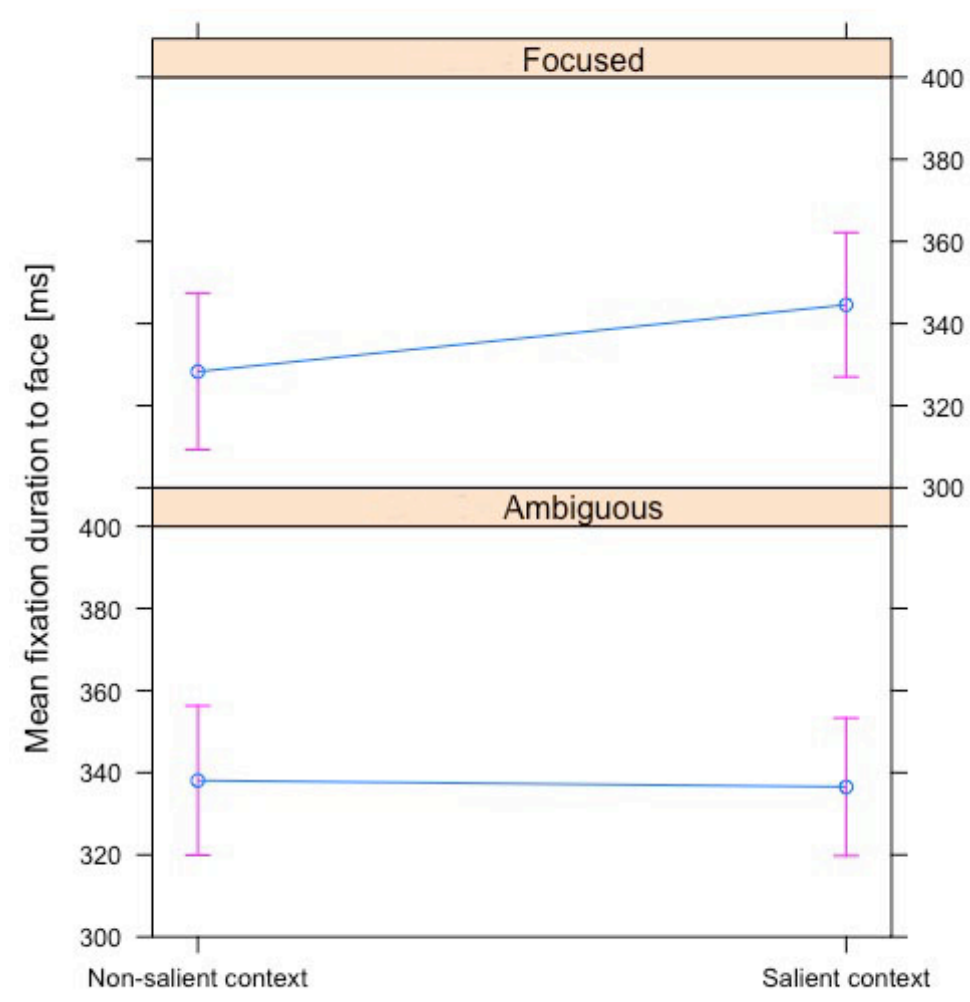

Figure 3. The mean fixation duration (in ms with $95 \% \mathrm{CI}$ ) to face ROIs in portraits. The data are shown for both type of Gaze (ambiguous versus focused) and the presence of salient features in the context (salient context versus non-salient context). 


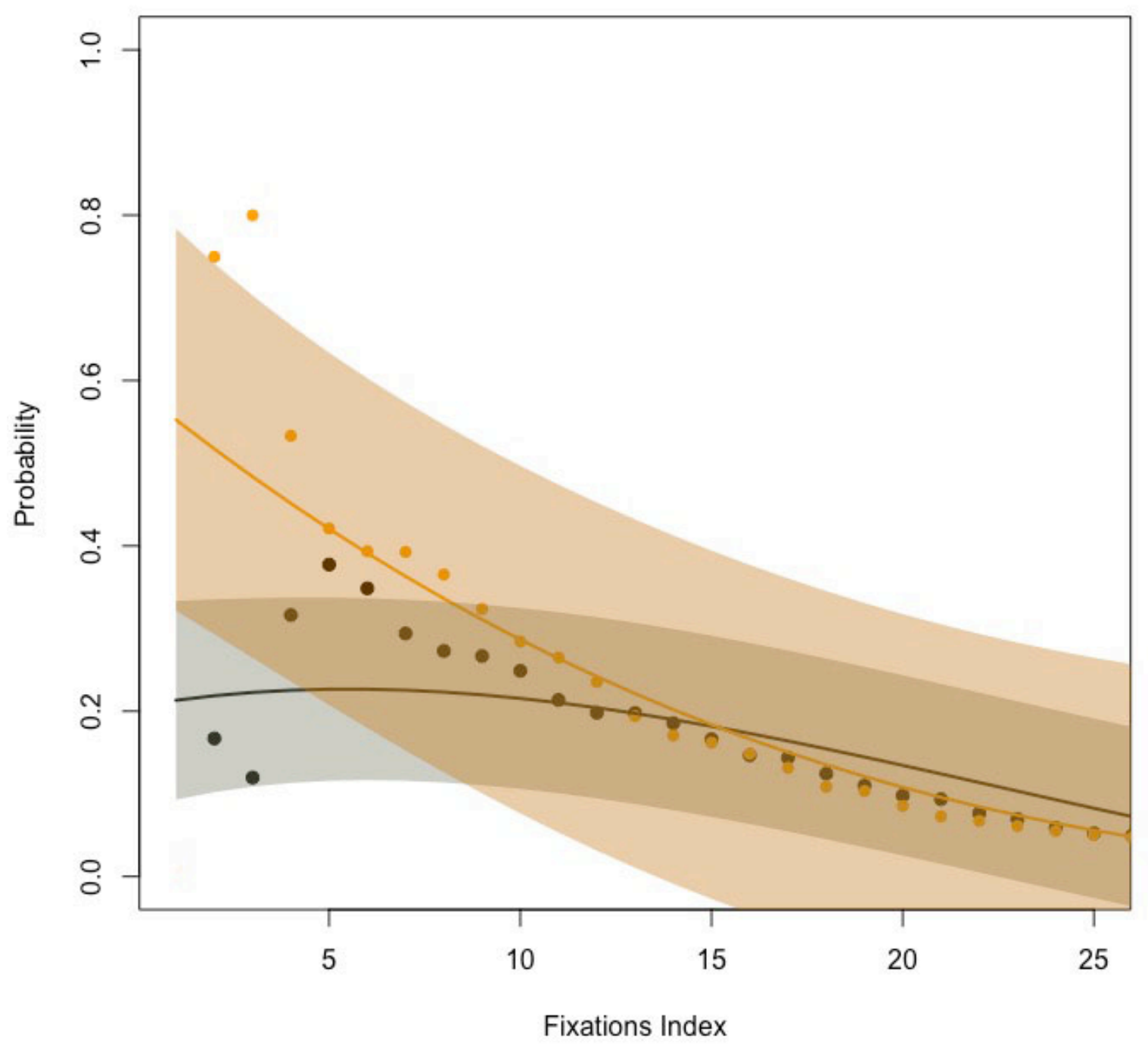

Figure 4. Probability of sampling information from the body (black line) and face ROIs (orange line). The shading area around function refers to $95 \%$ confidence interval. 


\section{Footnotes}

1. A similar conclusion emerges from work exploring how faces attract attention in more standard experimental paradigms (see Theeuwes \& Van der Stigchel, 2006).

2. The translation process consisted of a multistep process using a standardized methodology (Harkness \& Schoua-Glusberg, 1998). In the first step a draft English version of the Art Questionnaire was prepared. One German native speaker developed this version with comments and changes. Two experts in the psychology of art modified the English translation in terms of the use of simple and correct language. A second German native speaker then translated the questionnaire back into German. A third native German speaker, judged the coherence between these two German versions. The level of similarity was evaluated for each sentence from 1 to 6 with each sentence scoring under 5 being retranslated. Taking note of the comments of this third native German speaker, six sentences were re-translated. A final meeting with the same two experts in psychology of art produced the definitive English translation of the German questionnaire.

3. Ratings for the 94 portraits used in Donnelly et al. (2017) correlate significantly with those gained in the present study $(r(94)=.59, p<.001)$. In addition, tests using the normal approximation to the binomial distribution confirm the findings of Donnelly et al. (2017) that gaze ambiguity is more common in portraits by Manet than in the combined set of Courbet and Fantin-Latour $(z=2.13, p<.05)$. Splitting the Courbet and Fantin-Latour set shows this contrast with Manet to remain significant for Courbet $(z=6.38, p<.001)$ but to be only a trend for Fantin-Latour $(z=1.70, p=.089)$. 
4. A portrait could have multiple ROIs of faces and bodies if more than one person was present in the portrait.

5. In the LMM model for ROIs (face vs. body vs. context), the random structure was (1। Subject $)+(1 \mid$ Stimuli) with respect to both normalised number of fixations and mean fixation duration. With respect to eye movement measures the random structure for the GLM of binary transformed number of fixations for body and context it was $(1 \mid$ Subject $)+(1 \mid$ Stimuli). The random structure in the GLM of binary transformed mean fixation duration for body was $(1+$ gaze $\mid$ Subject $)+(1 \mid$ Stimuli $)$ and for context it was $(1 \mid$ Subject $)+(1 \mid$ Stimuli). For eye movement measures the random structure for the LMM for log-transformed normalised number of fixations for face it was $(1 \mid$ Subject $)+(1 \mid$ Stimuli $)$, for body it was $(1+$ gaze $\mid$ Subject $)+(1 \mid$ Stimuli $)$ and for context it was $(1+$ gaze + saliency $\mid$ Subject $)+(1 \mid$ Stimuli). With respect to log-transformed mean fixation duration for faces, body and context the random structure in the LMM was $(1 \mid$ Subject $)+(1 \mid$ Stimuli). 
Appendix 1

Art Questionnaire

Questionnaire

Code:

Age:

Gender:

Thank you very much for taking part in this study.

In our studies, we would like to examine both, individual aesthetic preferences and the process of aesthetic experience. We are aware that aesthetic preferences and assessments are not independent of whether one is interested in art, design, etc., and what prior knowledge the individual participant brings. Therefore, we ask you to complete the following questionnaire. At the beginning, you will find a series of very different statements, which deal in general with art and your interest in art. Please indicate how strongly you agree with each individual statement.

\begin{tabular}{|c|c|c|c|c|c|c|c|c|c|}
\hline \multirow[b]{3}{*}{$\begin{array}{l}\text { A work of art must be beautiful to me to } \\
\text { like it. }\end{array}$} & \multicolumn{9}{|c|}{ Degree of True } \\
\hline & \multicolumn{7}{|c|}{$\begin{array}{l}\text { completely } \\
\text { agree }\end{array}$} & \multicolumn{2}{|c|}{$\begin{array}{l}\text { completely } \\
\text { disagree }\end{array}$} \\
\hline & 0 & 0 & 0 & 0 & 0 & 0 & 0 & 0 & 0 \\
\hline $\begin{array}{l}\text { Works of art always have a meaning, only } \\
\text { sometimes you do not understand the } \\
\text { meaning. }\end{array}$ & 0 & 0 & 0 & 0 & 0 & 0 & 0 & 0 & 0 \\
\hline I enjoyed art lessons at school. & 0 & 0 & 0 & 0 & 0 & 0 & 0 & 0 & 0 \\
\hline $\begin{array}{l}\text { In my free time or for my studies I visit } \\
\text { events relating to art or art history. }\end{array}$ & 0 & 0 & 0 & 0 & 0 & 0 & 0 & 0 & 0 \\
\hline $\begin{array}{l}\text { I could do what many so-called artists } \\
\text { produce. }\end{array}$ & 0 & 0 & 0 & 0 & 0 & 0 & 0 & 0 & 0 \\
\hline I like talking about art with other people. & 0 & 0 & 0 & 0 & 0 & 0 & 0 & 0 & 0 \\
\hline $\begin{array}{l}\text { I have many friends who are interested in } \\
\text { art. }\end{array}$ & 0 & 0 & 0 & 0 & 0 & 0 & 0 & 0 & 0 \\
\hline I cannot stand ugly works of art. & 0 & $\mathrm{O}$ & 0 & 0 & 0 & 0 & 0 & 0 & 0 \\
\hline $\begin{array}{l}\text { I like to read texts from artists or about } \\
\text { art in general. }\end{array}$ & 0 & 0 & 0 & 0 & 0 & 0 & 0 & 0 & 0 \\
\hline
\end{tabular}




\begin{tabular}{|l|l|l|l|l|l|l|l|l|l|}
\hline Modern art is often preposterous. & 0 & 0 & 0 & 0 & 0 & 0 & 0 & 0 & 0 \\
\hline $\begin{array}{l}\text { Art should portray things as accurately as } \\
\text { possible. }\end{array}$ & 0 & 0 & 0 & 0 & 0 & 0 & 0 & 0 & 0 \\
\hline I am interested in art. & 0 & 0 & 0 & 0 & 0 & 0 & 0 & 0 & 0 \\
\hline Art should be mainly decorative. & 0 & 0 & 0 & 0 & 0 & 0 & 0 & 0 & 0 \\
\hline $\begin{array}{l}\text { I look for new artistic impressions and } \\
\text { experiences repeatedly. }\end{array}$ & 0 & 0 & 0 & 0 & 0 & 0 & 0 & 0 & 0 \\
\hline $\begin{array}{l}\text { It is often the case that in my day-to-day } \\
\text { life I spontaneously notice an art object } \\
\text { which fascinates me. }\end{array}$ & 0 & 0 & 0 & 0 & 0 & 0 & 0 & 0 & 0 \\
\hline \begin{tabular}{l} 
I often go to art exhibitions. \\
\hline
\end{tabular} & 0 & 0 & 0 & 0 & 0 & 0 & 0 & 0 & 0 \\
\hline $\begin{array}{l}\text { I came from a family that is interested in } \\
\text { art. }\end{array}$ & 0 & 0 & 0 & 0 & 0 & 0 & 0 & 0 & 0 \\
\hline $\begin{array}{l}\text { Artists and their works are so diverse that } \\
\text { they should be viewed 'with different } \\
\text { eyes' over and over again. }\end{array}$ & 0 & 0 & 0 & 0 & 0 & 0 & 0 & 0 & 0 \\
\hline
\end{tabular}

What do you understand by "Modern" in relation to art?

Since the stimuli to be assesse were exclusively portrayals of paintings, we would like to know how knowledgeable you are in the field of art. This is not a test. The information you provide will help us evaluate your ratings in more detail.

In the table below you will find the names of some artists. Please indicate for each artist whether you know at least their name. As far as you know, please indicate also the artist's nationality and which artistic style is mainly associated with these artists.

If you are not sure, you may guess.

\begin{tabular}{|l|l|l|l|}
\hline artist's name & $\begin{array}{c}\text { know } \\
\text { (yes/no) }\end{array}$ & nationality & artistic style \\
\hline Henri Matisse & & & \\
\hline Joseph Beuys & & & \\
\hline Salvador Dali & & & \\
\hline Pablo Picasso & & & \\
\hline
\end{tabular}




\begin{tabular}{|l|l|l|l|}
\hline Jackson Pollock & & & \\
\hline Piet Mondrian & & & \\
\hline $\begin{array}{c}\text { Ernst Ludwig } \\
\text { Kirchner }\end{array}$ & & & \\
\hline Andy Warhol & & & \\
\hline Victor Vasarely & & & \\
\hline Anselm Kiefer & & & \\
\hline
\end{tabular}

Finally, we will show you a selection of pictures from modern artists. Please indicate again whether you know the pictures. As far as you know please also indicate the painter of the painting. In the last column, please indicate with which artistic style you associate the paintings.

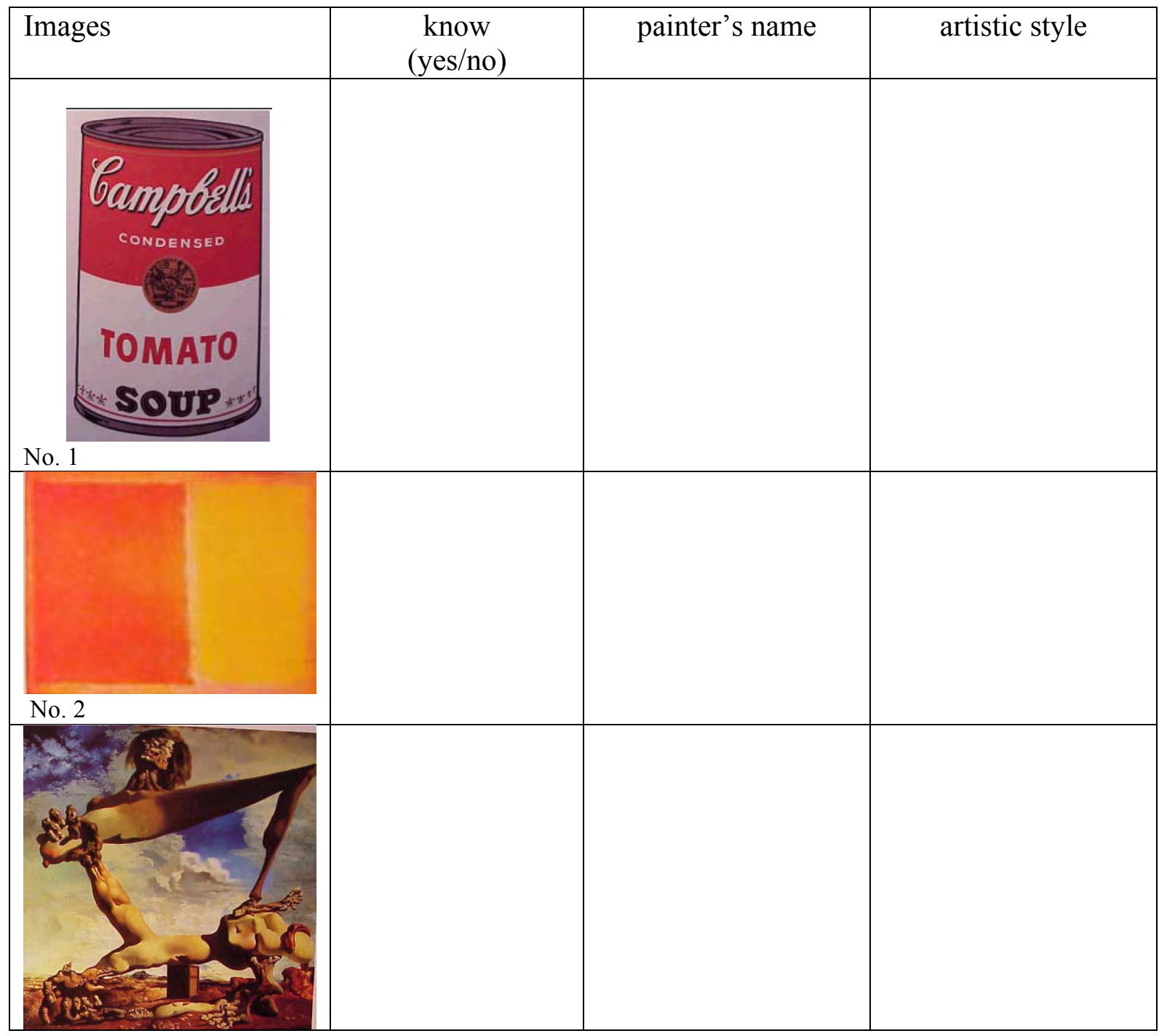




\begin{tabular}{|l|l|l|l|}
\hline No. 3 & & \\
\hline
\end{tabular}

\begin{tabular}{|l|l|l|l|l|}
\hline \multicolumn{2}{|l|}{ Images } & $\begin{array}{c}\text { know } \\
\text { (yes/no) }\end{array}$ & painter's name & artistic style \\
\hline & & & & \\
\hline No. 4 & & & \\
\hline & & & & \\
\hline No. & & & \\
\hline
\end{tabular}


Appendix 2

Instructions to participants for the pre-test when rating ambiguity of gaze of the primary sitter in the portraits

Eyes are typically aligned to fixate an object or face. This is evident when the pupils are aligned so that they focus on a single point in space. Humans are very good at knowing where others are looking, regardless of whether they are the subjects of that gaze or the gaze is directed at another point. Sometimes the two eyes do not align to allow us to confirm a single point of fixation. When this is the case, the shared focal point of the two eyes is difficult to determine. We refer to this difficulty as an ambiguity of gaze. You are asked to categorize whether the primary figure in each of the paintings presented has a pattern of gaze where the eyes are aligned or are not aligned. Sometimes a failure to align occurs because the pupils do not align on the horizontal axis (e.g. one pupil points further left than expected given the other pupil). Sometimes they fail to align on the vertical axis (e.g. one pupil points further up than the other). We are interested in exploring the gaze in a series of portraits, with reference to the primary figure in each painting (ignore any other figures in the scene). You will be asked to answer to question for each portrait and respond using the number keys on the keyboard." 